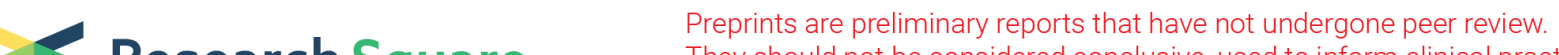 Research Square They should not be considered conclusive, used to inform clinical practice, or referenced by the media as validated information.
}

\section{Immunoprofiling in Breast Cancer \\ Microenvironment with Multiplexed \\ Immunofluorescence}

\section{Yalong Yang}

Wuhan University

Chengxin Li

Wuhan University

Xingxing Dong

Wuhan University

Qianqian Yuan

Wuhan University

Jiuyang Liu

Wuhan University

Gaoran Xu

Wuhan University

Jinxuan Hou

Wuhan University

Yan Gong

Wuhan University

Gaosong Wu ( $\nabla$ wugaosongtj@163.com )

Zhongnan Hospital of Wuhan University https://orcid.org/0000-0001-9296-7080

\section{Research}

Keywords: breast cancer, immune cell, tumor microenvironment, multiplexed immunofluorescence, macrophage

Posted Date: January 18th, 2022

DOI: https://doi.org/10.21203/rs.3.rs-1223742/v1

License: (c) (1) This work is licensed under a Creative Commons Attribution 4.0 International License.

Read Full License 


\section{Abstract \\ Background}

The immunoprofiles in tumor microenvironment (TME) has established impacts on the tumorigenesis, metastasis, therapy sensitivity and prognosis in various solid tumors, including breast cancer. Regulation of local immune cell homeostasis is considered as a promising strategy for breast cancer therapy.

\section{Aim}

Comprehensively investigate the landscape of tumor-infiltrated immune cells in breast cancer and benign tissues, and provide novel evidence for potential immunotherapy strategies.

\section{Method}

A total of 140 pairs of breast cancer and benign tissues were collected and sectioned. The multiplexed immunofluorescence was applied to simultaneously analyze the immunoprofiles in breast cancer TME. Images were captured by AKOYA-Vectra 3 and analyzed with InForm 2.1 software.

\section{Results}

Comparing the general benign with malignant samples, the mean percentages of T cells $(17.03 \% \mathrm{vs}$ $14.85 \%, p=0.2329)$, B cells ( $6.406 \%$ vs $3.763 \%, p=0.0189)$, and macrophages $(17.06 \%$ vs $27.1 \%, p=0.008)$ showed dramatic difference. In addition, we compared segmental areas, para-cancer with cancer tissues, different pathological and molecular types, and found that the main difference was the proportion of macrophages, especially the M2 subtype.

\section{Conclusion}

Macrophages and M2 subtype were the iconic differentiated infiltrating immune cells in breast cancer, especially related with the malignancy, clinic stages and tumorigenesis, which was the promising target in cancer therapy.

\section{Introduction}

Breast cancer is currently the leading malignancy with the highest incidence around $11.7 \%$ worldwide [1]. In addition to the traditional pathological diagnosis and discrimination of breast cancer, more precise molecular classification, including estrogen receptor (ER), progesterone receptor (PR), human epidermal growth factor receptor (HER) 2 and Ki-67, has promoted the treatment of breast cancer into a precision 
medicine and individualized therapy era [2]. However, special types of breast cancer, such as triplenegative breast cancer (TNBC), inflammatory breast cancer and endocrine therapy-resistant breast cancer, still have a high mortality $[3,4]$. The immunoprofiling in the tumor microenvironment (TME) has established impacts on the tumorigenesis, metastasis, therapy sensitivity and prognosis in various solid tumors, including breast cancer $[5,6]$.

Tumor-associated immune cells cover a wide range of cell types, such as tumor infiltrating lymphocytes, tumor-associated macrophages (TAMs), and natural killer (NK) cells [7, 8]. Regulation of the local immune cells is considered as a promising treatment in breast cancer and other solid tumors [9]. Recently, the studies of immune checkpoints improved the clinical application of their inhibitors in tumor therapy, and achieved positive feedback in breast cancer [10]. The application of programmed cell death protein (PD)-1 and PD-1 ligand 1 (PD-L1) inhibitors partially ameliorated breast cancer patient conditions [11]. Regrettably, accumulating data from clinical studies indicated that immune checkpoint inhibitors showed low sensitivity and high resistance in breast cancer patients [12]. Thus, it is urgent to reveal the mechanisms and profiles of immune cells in the TME of breast cancer, such as CD $4^{+} \mathrm{T}$ cells, CD $8^{+} \mathrm{T}$ cells, B cells, NK cells, macrophages and T regulatory cells (Tregs).

Numerous studies have studied different types of immune cells both in local cancer niche and peripheral circulatory system with flow cytometry or immunohistochemistry $(\mathrm{IHC})$ in breast cancer $[13,14]$. However, ambiguous or even contrary conclusions were obtained with various novel cell markers, especially in the analysis of macrophage subtypes [15-18]. Revealing the characteristics of immune cells in breast cancer microenvironment is a prerequisite for further research on treatments and interventions.

Here we collected 140 breast tissues and synchronously investigated the differentiated immune profiles of different pathological or molecular types using multiplexed immunofluorescence/immunohistochemistry $(\mathrm{Ml} / \mathrm{IHC})$. According to the results of $\mathrm{MI} / \mathrm{IHC}$ immunoprofiles, we further investigated the correlation of these immune cells with breast cancer using the TCGA database, and proposed the potential transcription factors or metabolism-related genes as targets in immune cell regulation.

\section{Results}

\subsection{Quality control and analysis flow chart}

First, we verified the recommended concentrations of each antibody with breast cancer or tonsil tissue sections, which contained abundant macrophages, $T$ cells and B cells. The concentration of individual antibody was adjusted using typical IHC method with low levels of non-specific background staining to maximally reduce the fluorescent intensity of non-specific signal (SFigure 1). A total of 151 samples were collected in a tissue chip with 1-mm diameter of each dot. All the detailed information of pathological type, clinical stage, lymph node metastasis, tumor size and molecular type were listed in STable1. After staining, 133 dots were analyzed, and 18 dots were collapsed, spoiled or multilevel stained, highlighted in 
red in STable1. The merged images were then split into single fluorescent channel with changeable colors to compensate individual signal (Figure 1A), and were analyzed with InForm analysis software as working flow chart (Figure 1B).

\subsection{Immune phenotype analysis in breast cancer 2.2.1. Immunoprofiles between non-carcinoma and carcinoma tissues}

The immunoprofiles were compared between non-carcinoma and carcinoma tissues both in total and segmental areas according to the pathological diagnosis. In the total area of non-carcinoma breast tissues, percentages of $\mathrm{CD} 68^{+}$macrophages and $\mathrm{CD}^{+} \mathrm{T}$ cells were much higher than those of $\mathrm{CD} 19^{+} \mathrm{B}$ cells (mean values, $17.06 \%$ vs $6.406 \%$, and $17.03 \%$ vs $6.406 \%$, $\mathrm{p}<0.005$ ), and $\mathrm{CD} 68^{+} \mathrm{CD} 163^{+} \mathrm{M} 2$ macrophages were more than CD68 ${ }^{+} \mathrm{TLR}^{+} \mathrm{M} 1$ macrophages (mean values, $10.64 \%$ vs $4.852 \%$, $\mathrm{p}=0.0007$ ) in benign breast samples (SFigure 2B). Interestingly, $\mathrm{CD} 68^{+} \mathrm{CD} 40^{+} \mathrm{TAMs}$ were less than $\mathrm{M} 2$ macrophages (mean values, $10.64 \%$ vs $4.666 \%, p=0.0001$ ) in the benign diseases (SFigure $2 \mathrm{C}$ ). In the gland or para-gland areas, percentages of $\mathrm{CD} 68^{+}$macrophages and $\mathrm{CD} 3^{+} \mathrm{T}$ cells were much higher than

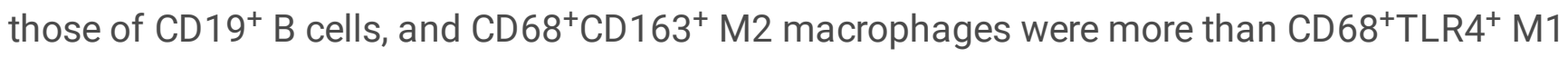
macrophages ( $95 \% \mathrm{Cl}$ of difference, $2.364 \%$ vs $10.1 \%, p=0.002)$, which was similar to the general immunoprofiles of the total areas (SFigure 2B). However, the stromal areas displayed harmonious immunoprofiles, including macrophages (SFigure 2B). Of note, in the benign tissues, immune cells were mainly located in the gland or para-gland areas, which was obviously contrary to the carcinoma samples (Figure 2A and SFigure 2A).

Meanwhile, we analyzed the carcinoma samples like non-carcinoma manner. We found that different from benign samples, macrophages were the highest immune cell type in malignant samples (Figure 2B). The sub-phenotypes of macrophages also showed similar ratio, M2 was higher than M1 and TAM, while TAM and M1 had no obvious difference (Figure 2B). Next, we analyzed the segmental areas and found that in the tumor/gland areas, $\mathrm{CD} 68^{+}$macrophages were the highest immune cells unlike in noncarcinoma samples (Figure $2 \mathrm{C}$ and 2D). We found that in the stromal areas, macrophages were also higher than T cells and B cells, and that the M2 subtype was higher than M1 and TAM (Figure 2C). As we mentioned, the immune cells in cancer samples were mainly localized in the stromal areas compared with benign samples (Figure 2A).

Comparing non-carcinoma samples with carcinoma samples, we found that $\mathrm{T}$ cells showed no difference, and that macrophages increased significantly in TME (Figure 2D). However, the proportion of $B$ cells was decreased in the tumor samples (Figure 2D). The percentages of each subtype of macrophages decreased in carcinoma tissues compared with non-cancer samples (Figure 2E). Additionally, when we divided the samples into tumor/gland or stromal areas, we found contrary immunoprofiles between the benign and malignant samples. In the tumor/gland areas, the percentages 
of $T$ cells, B cells and macrophages were decreased significantly in the TME, as well as all the macrophage subtypes (Figure $2 \mathrm{~F}$ and $2 \mathrm{G}$ ). While in the stromal areas, macrophages were much higher in the cancer samples than non-cancer ones (Figure 2F and 2G). Of note, in the stromal areas of tumor samples, M2 macrophages were increased dramatically as well as the other two subtypes (Figure 2F and $2 G)$.

In a short summary, macrophages were increased in the stromal areas rather than gland or para-gland areas, of which the M2 subtype was the dominant part. Furthermore, tumorigenesis disturbed the equilibrium of different macrophage subtypes in the stromal areas of benign samples, which was the hallmark of tumoral immunoprofiles.

\subsubsection{Immunoprofiles among different pathological types of benign and malignant tissues}

In addition to the difference between the benign and malignant tissues, we further compared the immunoprofiles among different pathological types. First, we compared benign breast samples' adenosis, fibroadenoma, and chronic mastitis. Generally, among these three common benign diseases, the percentages of T cells, B cells and macrophages showed no obvious difference, even the subtypes of macrophages (SFigure 3A). Individual pathological type of these benign tissues showed similar immunoprofiles that macrophages and M2 subtypes were the dominant immune cells, which were mainly localized in the gland areas (SFigure 3B-D). Our carcinoma samples included 7 pathological types, namely ductal carcinoma in situ (DCIS), non-specific invasive carcinoma, metaplastic carcinoma, papillary microcarcinoma, characteristic neuroendocrine carcinoma, invasive lobular carcinoma and medullary carcinoma. Results showed that macrophages were the most differentiated immune cells among different pathological types (Figure 3A). Characteristic neuroendocrine carcinoma had slightly more T cells than non-specific invasive and metaplastic carcinoma (Figure 3A). Percentages of B cells were comparable among different pathological types, except DCIS and non-specific invasive carcinoma (Figure 3A). The total percentages of macrophages seemed to display a malignant-degree-related manner, namely DCIS was lower than all other non-DCIS samples except for papillary microcarcinoma (Figure 3A). Interestingly, the M1 subtype displayed significantly higher percentages in non-specific invasive carcinoma and invasive lobular carcinoma than medullary carcinoma, which mainly functioned as anti-tumor cells (Figure 3B). On the contrary, the M2 subtype was much lower in DCIS than nonspecific invasive and metaplastic carcinoma, as tumor-promoting cells (Figure 3B). Of note, leach pathological type of cancer samples showed sundry immune profiles with similar general characteristics, that macrophages were the major cells in stroma areas (SFigure 4).

According to the above results, we found that different pathological types generally had similar immunoprofiles, especially in the benign diseases. However, the percentages of macrophages and M2 subtype in the malignant tissues were increased in a malignant-degree-related manner.

\subsubsection{Immunoprofiles among different molecular types of malignant tissues}


During past decades, molecular classification ameliorated the therapy of breast cancer in addition to the pathological diagnosis [2]. Thus, we next compared the immunoprofiles among different molecular types of malignant tissues, namely Luminal A, Luminal B, HER2 positive and TNBC types. Generally, T cells, B cells and macrophages showed no obvious difference among the four molecular types (Figure 4A). Notably, both $\mathrm{CD} 68^{+} \mathrm{CD} 163^{+} \mathrm{M} 2$ and $\mathrm{CD} 68^{+} \mathrm{TLR}^{+} \mathrm{M} 1$ macrophages had the lowest proportions in TNBC (Figure 4A). Furthermore, we separately analyzed the immunoprofiles in tumor/gland or stromal areas. B cells showed higher percentages in HER2 positive than TNBC and Luminal types in the stromal areas (Figure 4B). In the stromal areas, both $\mathrm{CD} 68^{+} \mathrm{CD} 163^{+} \mathrm{M} 2$ macrophages and $\mathrm{CD} 68^{+} \mathrm{CD} 40^{+}$TAMs were upregulated in the HER2 positive type than the Luminal types (Figure 4B). However, the tumor/gland or adjacent areas showed no significant discrepancy during these molecular types (Figure 4B). We also analyzed the immune cells in a single molecular type, and they showed similar proportions of immune cells as general cancer immunoprofiles, except the macrophage subtypes in TNBC (SFigure 5).

In a short conclusion, comparing the immunoprofiles of different molecular types, macrophages and their subtypes showed the dominant difference, especially in TNBC and HER2 ${ }^{+}$types.

\subsubsection{Immunoprofiles between para-cancer and cancer tissues}

From the above results, we could conclude that different molecular types, pathological types and noncarcinoma tissues mainly had infiltrating differences in macrophages. Some recent bioinformatic analysis indicated that para-cancer tissues also had genetic mutations at the initial phase or development stage $[19,20]$. Thus, we further compared the corresponding para-cancer with cancer tissues. The proportions of T cells, B cells and macrophages showed no difference between para-cancer and cancer tissues (Figure 5A). But all the three subtypes of macrophages in the para-cancer tissues were much higher than those in the cancer tissues (Figure 5A). However, the immune cells in para-cancer showed similar characteristic with benign samples (Figure 5B and 5C). Our data here indicated that the para-cancer tissues had different immunoprofiles with cancer tissues, which was more similar with benign tissues, and macrophage subtypes showed significant differences with cancer tissues.

\subsubsection{Immunoprofiles among different clinical stages}

At last, we divided samples into three clinic stages according to the size of tumor and lymphatic metastasis, namely stage I, II and III. Due to the limited number of DCIS cases, we combined DCIS and stage I together in our analysis. We found that macrophage levels were apparently higher in stage III than stage $\mathrm{I}$, while $T$ cells and $B$ cells showed no obvious difference (Figure $6 \mathrm{~A}$ ). Furthermore, during the development from DCIS and stage I to stage II or III, the percentages of both M2 and M1 macrophages were significantly increased, and TAM displayed decreased tendency (Figure 6B). However, when we separately analyzed the immune cells in the tumor/gland and stromal areas, T cells, B cells and macrophages showed no difference in separate areas (SFigure 6). 


\subsubsection{Bioinformatic analysis of immune cells in breast cancer}

According to our above data, macrophages and M2 subtype were the iconic immune cell types in breast cancer during tumorigenesis and development. Thus, we applied bioinformatic analysis using TCGA and GEO database to further analyze their prognostic values and potential regulatory pathways of macrophages in breast cancer. Results showed similar changes with our $\mathrm{MI} / \mathrm{IHC}$ data. Macrophage/M0 was much higher in tumor tissues than non-cancer ones, and B cells were lower in tumor tissues (Figure 7A). We further divided T cells into subtypes, which showed contrary changes among each other in the TME (Figure 7A). Interestingly, from the TCGA database we found that tumor tissues had higher M1 and lower M2 than normal ones, which contrasted with the previous hypothesis [21] but was consistent with our data (Figure 7A and 2C). Furthermore, we compared the individual immune cell type among different molecular types, and found that TNBC showed the most significant difference, that TNBC had lower infiltrating levels of $B$ cells than Luminal $A$ and $B$, and showed the highest levels of $M 0$ and $M 1$, while the lowest level of M2 (Figure 7B). Next, we divided the infiltrating cells into high and low levels, and investigated the survival correlation with breast cancer. Results showed that except for B cells, only M2 macrophages showed significantly negative influence on the survival rate (Figure $7 \mathrm{C}$ ). Corresponding to the abundance of $B$ cell subtypes, their infiltrating levels displayed contrary relationships with survival rates between the two subtypes (Figure 7C). Additionally, we used COX Multivariate and Univariate analysis to further investigate the outcomes of $\mathrm{M} 2$ in breast cancer together with other well-known clinic factors, TNM, age, stage and molecular types. M2 macrophages showed the strongest indicated values in breast cancer outcomes (Table 1).

Meanwhile, we compared 3875 differentially expressed genes (DEGs) between breast cancer and normal tissues identified based on the GSE42568 dataset from GEO database with 1793 immune related genes (IRGs) acquired from the ImmPort database, and obtained 268 genes overlapped (Figure 8A and B). We further constructed protein-protein interaction (PPI) network of these 268 genes and screened out the most significant module. Then, we analyzed the biological functions of genes included in this module, and found that IRF3 (interferon regulatory factor 3), IRF7 and NOD2 (Nucleotide Binding Oligomerization Domain Containing 2) were upregulated in macrophage apoptosis process of breast cancer (Figure $8 \mathrm{C}$ and D).

\section{Discussion}

Breast cancer is the prevalent carcinoma in human and the immunoprofile in TME has been proven to play critical roles in tumor occurrence, development, prognosis and treatment $[5,6]$. Infiltrating immune cells contain T cells (CD4 T resting, CD4 T activate, Tregs, T helper, CD8 and TY- $\delta$ ), B cells (B naive and memory), macrophages (M0, M1 and M2), NK cells (NK resting and activate), DC cells (DC resting and activate), monocytes, neutrophils and eosinophils [22-25]. Studies indicated that macrophages had a wide range of subtypes in past decades with various cell markers, such as CD206, CD64, MHC , MerTK, 
Siglec-1, Ly6C, Lyve1 and CX3CR1 [26-28]. Due to different localized environments or precipitating factors, macrophages were divided into more sophisticated subtypes, such as M2a, M2b, M2c, M2d and TAM [29]. TAMs were under the intense discussion for decades due to high heterogeneity and various functions in different cancer models [30, 31]. Appearing cell markers for TAMs, such as CD206, PM-2K, CD40, COX2 and CCR2, led to deeper investigations of tumor associated macrophages [32-34].

In the current study, we used typical cell markers for different immune cell types, namely CD3 for T cells, CD19 for B cells, CD68 for macrophages, $C D 68^{+} \mathrm{TLR}^{+}$for M1, $\mathrm{CD} 68^{+} \mathrm{CD} 163^{+}$for $\mathrm{M} 2$ and $\mathrm{CD} 68^{+} \mathrm{CD} 40^{+}$ for TAM, to investigate the detailed immunoprofiles of breast cancer with $\mathrm{MI} / \mathrm{IHC}$ method, compared with non-carcinoma, para-cancer and different pathological and molecular types. However, the selection of macrophages subtypes, especially TAMs, was still ambiguous, because studies showed that TAMs resembled not only $\mathrm{M} 2$ subtype, but also contained M1-like subtype with diverse cell markers [35, 36]. Of note, in the benign samples of this study, we also clearly identified the $\mathrm{CD} 68^{+} \mathrm{CD} 40^{+} \mathrm{TAM}$ subtype (SFigure 2A, green arrows). Thus, the novel and specific TAM cell markers are still urgent need to be found.

We collected 140 cases of breast tissues containing benign and malignant diseases, but we only had two DCIS and two male patients, which had limitations in investigating these clinic classifications. Also, we lost 18 samples during the staining process. However, our available samples were statistically sufficient with molecular equilibrium and pathological types. Similar with the bioinformatic analysis results (Figure 7), our sample generally indicated the immunoprofiles of breast cancer, and even showed more precise differences among various sample types.

Compared between benign and malignant samples, our data indicated that the immune cells transferred from gland/para-gland to stromal areas (Figure 2 and SFigure 2) and the percentages of macrophages and T cells increased significantly, while B cells decreased (Figure 2). Studies showed that regulations of interstitial components of tumor tissues were crucial to tumorigenesis and metastasis [37, 38], and our data further verified the re-localization of immune cells, especially M2 in altering the TME and promoted the tumor-promoting changes in the matrix formation and angiogenesis [39-41]. Due to the shortage of $\mathrm{Ml} / \mathrm{IHC}$ method, we did not further classify subtypes of $\mathrm{T}$ cells and $\mathrm{B}$ cells, which might show diverse infiltrating levels as results of bioinformatic analysis (Figure 7). In the current study, we concluded that $\mathrm{M} 2$ was the highest subtype in tumor environment than M1 and TAM (Figure $2 \mathrm{C}$ and $2 \mathrm{G}$ ). However, some studies indicated that TAM was the dominant macrophage subtype in breast cancer [42]. First of all, as discussed above, different cell markers used to label TAMs contributed to the contrary results, even regarding $\mathrm{CD}^{206^{+}}$or $\mathrm{CD} 163^{+}$as TAM, which was normally regarded as M2 markers $[34,43]$. Second, we found that even $\mathrm{T}$ cells or $\mathrm{B}$ cells showed overlapped staining with both $\mathrm{CD} 3^{+}$and $\mathrm{CD} 19^{+}$in $\mathrm{MI} / \mathrm{IHC}$. We analyzed the immune cell phenotypes using double-positive mode, during which we discarded the nonspecific double-positive cells and only count single positive cells. Of note, we found that $\mathrm{CD} 68^{+} \mathrm{CD} 40^{+}$ TAM also had CD163 or TLR4 positive binding, indicating that TAMs had a high level of heterogeneity. 
By comparing benign with malignant samples, different pathological types, molecular types, para-cancer with cancer samples, and different stages, our study indicated that macrophages, especially the M2 subtype, were the most obviously regulated immune cells that were stably and highly expressed in breast cancer with a malignant degree-dependent manner. Some studies also correlated the percentages of M2 in peripheral circulation with the poor prognosis in breast cancer patients [44]. Our MI/IHC data together with bioinformatic analysis results consistently further indicated that the infiltrating levels of M2 were correlated with tumorigenesis and malignant degree. To further investigated the macrophage regulation or differentiation mechanisms, we compared the DEGs between breast cancer and normal tissues, overlapped with immune-related gene database, and obtained 26 potential DEG-IRGs (Figure 8). Combining our data of macrophage characteristics, we further applied GO analysis targeting macrophage biological regulations, and obtained single macrophage related biological function, namely macrophage apoptosis process, IRF3, IRF7 and NOD2 were all upregulated in breast cancer. IRF3 and IRF7 were key transcription factors involving in diverse pathways, including immune regulation, interferon response, and viral response $[45,46]$. NOD2 is a member of the Nod1/Apaf-1 family, and was mainly involved in the inflammatory response and NFKB activation [47]. Their dysregulation in breast cancer and correlation with macrophage functions indicated the potential targeting values in cancer therapy.

\section{Conclusion}

In summary, the current study investigated the immunoprofiles of breast cancer by applying a more efficient method, multiplexed immunofluorescence staining, compared with benign samples and within diverse molecular types. We found that macrophages, especially M2 subtype rather than TAM, showed dramatic differences during tumorigenesis and development, and also displayed a malignancy-related pattern. Bioinformatic analysis further verified that M2 subtype was closely related with breast cancer survival rate. IRF3, IRF7 and NOD2, in the regulation pathway of macrophages, were promising gene targets in the future studies.

\section{Methods \\ 5.1. Patients}

The $\mathrm{MI} / \mathrm{IHC}$ in this study was performed with a tissue chip, produced with breast tissues from 151 patients from Zhongnan Hospital containing benign and malignant cases. Patients with breast cancer accepted surgery and informed consent. This study includes 18 benign cases, 10 para-cancer samples and 123 malignant cases, which cover 37 Luminal A, 32 Luminal B, 35 HER2 $^{+}$and 19 TNBC subtypes according to the expression standard of National Comprehensive Cancer Network guideline in 2021 [48] (STable 1). Zhongnan Hospital approved the protocol of this study, and all the data obtained from patients were strictly complied with relevant ethical requirements.

\subsection{Multiplexed Immunofluorescence}


Multiplexed immunofluorescence was performed using PerkinElmer Opal 7-Color Manual IHC kit

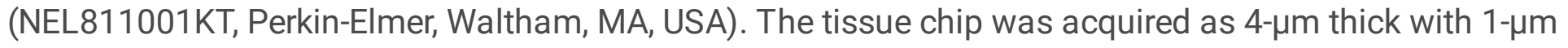
diameter of each sample. After deparaffinization, the chip section was rehydrated, antigen was restored in Tris-EDTA buffer ( $\mathrm{pH} 9.0$ ) using microwave, and $3 \%$ hydrogen peroxide was used to inactivate endogenous peroxidase. The following steps of multiplexed IHC were followed consecutively for each marker: blocked non-specific markers with goat serum (G9023, Sigma, USA), followed by incubation with primary antibody for $1 \mathrm{~h}$, detection using Opal Polymer HRP Ms/Rb secondary antibody (PerkinElmer, Waltham, MA, USA), and visualization using Opal tyramide signal amplification (TSA)-Fluorescein (diluted with Amplification Dilution), after which the section was placed in 1×AR6 Buffer and heated using microwave. The primary antibodies and corresponding TSA used for each protein were as follows: Opal 520 for anti-CD3 (60181-1-lg), Opal 540 for anti-CD68 (66231-2-lg), Opal 570 for anti-CD163 (166461-AP), Opal 620 for anti-CD19 (66298-1-lg), Opal 650 for anti-CD40 (66965-1-lg), and Opal 690 for antiTLR4 (22048, Abcam, Waltham, USA). The primary antibodies were purchased from Proteintech, Rosemont, USA unless mentioned. The methods have been introduced in details in previous studies [49].

\subsection{Multispectral Image Scanning and Quantitative Analysis}

After staining with 6 Opal TSA-Fluorescein and nuclear dying DAPI, the spectral information of the tissue chip was captured and split in the Vectra 3.0 Automated Quantitative Pathology Imaging System (PerkinElmer, Waltham, MA, USA). The stained section was scanned at 20x (multiplexed IHC and hematoxylin/eosin) including the total dot area of each sample. The image files created by Vectra were then analyzed using Inform 2.1 image analysis software (PerkinElmer, Waltham, MA, USA). Due to the heterogeneity during the tissue preparation and staining of 151 dots in the chip, it was inaccurate to set up one spectral library to bench analysis of all the samples instead of individual analysis. As shown in the analysis flow chart (Figure 1B), each fluorescent intensity was firstly adjusted to proper visual performance. The tumor/gland or stromal segment was then selected with classical histological characteristics, followed by automatic segment division. This step could be skipped, and the general/total immune profiles were investigated. Next, the analysis values of nucleus and cytoplasm were determined by nuclear size, nuclear splitting sensitivity, thickness of membrane and others to precisely select single cells. At least 5 typically positive cells of each single phenotype were selected, and the total sample dots were used for the cell phenotype map. Finally, the positive cell proportion was scored according to the fluorescent intensity in the double-positive analysis, exporting the percentage data of single positive of CD3, CD19 and CD68, and double-positive of CD68-CD163, CD68-TLR4 and CD68-CD40 for further analysis.

\subsection{Bioinformatic Analysis}

We downloaded RNA-seq data and clinical information of breast cancer from The Cancer Genome Atlas (TCGA, https://portal.gdc.cancer.gov), 1,109 cancer and 113 corresponding para-cancerous tissues were collected. To assess the tumor microenvironment in BRCA, we calculated 22 types of immune cells' abundances based on the CIBERSORT algorithm. We first performed differential immune cell infiltration analysis between cancer and para-cancerous tissues. The patients with survival time $\geq 30$ days were 
included in the survival analysis, and divided into high and low immune cell infiltration groups according to the median immune cell (macrophages, B cells, T cells) relative proportion. Survival curves were established using Kaplan-Meier analysis and compared by log-rank testing, $\mathrm{p}<0.05$ was considered as statistically significant. To assess whether the immune cell infiltration level can act as an independent prognosis-related factor, univariate Cox regression analysis and multivariate Cox regression analysis were performed, $p<0.05$ was considered as statistically significant. Furthermore, we evaluated the infiltration levels of immune cells in four different breast cancer subtypes: Basal-like $(n=139), \operatorname{HER}^{+}(n=43)$, Luminal A $(n=404)$, Luminal $B(n=178)$. Wilcox test was used to analyze the statistical significance and $p<0.05$ was considered as statistically significant.

Meanwhile, we also downloaded the GSE42568 dataset (raw CEL file and GPL file) from GEO database, which was based on GPL570 Platforms ([HG-U133_Plus_2] Affymetrix Human Genome U133 Plus 2.0 Array) and contained 104 primary breast cancer and 17 normal breast biopsies gene chips. After quality control, a total of 94 cancer samples and 14 normal breast samples were obtained, based on which, we identified the DEGs in breast cancer compared with normal samples using R package "limma" with log2Fold Change $>1$, adjust $p$-value $<0.05$. The IRGs were obtained from the ImmPort database (https://www.immport.org/home). Then, the Venn diagram was portrayed using an online tool (http://bioinformatics.psb.ugent.be/webtools/Venn/) to get the overlapping genes between DEGs and IRGs. Next, we employed the STRING (https://www.string-db.org) tool to construct PPI network of overlapping genes with Pearson correlation coefficient $\geq 0.4$ and reproduced the network using Cytoscape. Subsequently, plug-in MCODE of Cytoscape was used to detect the densely connected regions (i.e., modules) of networks, the criteria of which was a degree cut-off $=2, \operatorname{MCODE}$ scores $\geq 4$, Max. Depth=100, $\mathrm{k}$-score $=2$ and node score cut-off $=0.2$. Moreover, the enrichment analysis was performed with Metascape resource (http://metascape.org).

\subsection{Statistical Analysis}

The data were analyzed with the 2-way and one-way ANOVA with Tukey test or 2-tailed unpaired t-test to express the differences in immune cellular densities among various types or segments. GraphPad Prism 9 software (GraphPad, CA, USA) was used for statistical analyses. All $p<0.05$ were considered to be statistically significant.

\section{Abbreviations}

DCIS, ductal carcinoma in situ; DEGs, differentially expressed genes; ER, estrogen receptor; FC, flow cytometry; HER2, human epidermal growth factor receptor 2; IHC, immunohistochemistry; IRF3, interferon regulatory factor 3 ; IRGs, immune related genes; $\mathrm{MI} / \mathrm{IHC}$, multiplexed immunofluorescence/immunohistochemistry; NK, natural killer cells; NOD2, nucleotide binding oligomerization domain containing 2; PD-1, programmed cell death protein-1; PD-L1, PD-1 ligand 1; PPI, protein-protein interaction; PR, progesterone receptor; TAM, tumor-associated macrophage; TNBC, triple- 
negative breast cancer; TME, tumor microenvironment; Treg, T regulatory cells; TSA, tyramide signal amplification.

\section{Declarations}

Ethics approval and consent to participate

Patient consent was waived because the study used archived samples from patients who had already agreed to donate samples for research, and data were encrypted and provided to researchers without being able to identify personal information by a third party.

Consent for publication

Not applicable.

Authors' Contributions:

Conceptualization, GW and YG; methodology, YY, CL, XD and QY; bioinformatic analysis, CL, YY and XD; data analysis, $Y Y, G X, Q Y$ and JL; writing-original draft preparation, $Y Y, C L, J L$ and $X D$; writing-review and editing, GW, YG and JH; supervision, GW and YG; All authors have read and agreed to the published version of the manuscript.

Funding

There was no found for this study.

Availability of data and materials

All data generated or analyzed during this study are included in this published article and its supplementary information files.

Acknowledgments

Not applicable.

Conflicts of Interest

The authors declare no conflict of interest.

\section{References}

1. Sung H, Ferlay J, Siegel RL, Laversanne M, Soerjomataram I, Jemal A, Bray F. Global Cancer Statistics 2020: GLOBOCAN Estimates of Incidence and Mortality Worldwide for 36 Cancers in 185 Countries. CA Cancer J Clin. 2021 May;71(3):209-249. doi: 10.3322/caac.21660. Epub 2021 Feb 4. PMID: 33538338. 
2. Ross E, Swallow J, Kerr A, Chekar CK, Cunningham-Burley S. Diagnostic layering: Patient accounts of breast cancer classification in the molecular era. Soc Sci Med. 2021 Jun;278:113965. doi:10.1016/j.socscimed.2021.113965. Epub 2021 Apr 28. PMID: 33940433; PMCID: PMC8146724.

3. Hester RH, Hortobagyi GN, Lim B. Inflammatory breast cancer: early recognition and diagnosis is critical. Am J Obstet Gynecol. 2021 Oct;225(4):392-6. doi:10.1016/j.ajog.2021.04.217. Epub 2021 Apr 20. PMID: 33845027.

4. Blackley EF, Loi S. Targeting immune pathways in breast cancer: review of the prognostic utility of TILs in early stage triple negative breast cancer (TNbreast cancer). Breast. 2019 Nov;48 Suppl 1:S44S48. doi: 10.1016/S0960-9776(19)31122-1. PMID: 31839159.

5. Tseng YH, Ho HL, Lai CR, Luo YH, Tseng YC, Whang-Peng J, Lin YH, Chou TY, Chen YM. PD-L1 Expression of Tumor Cells, Macrophages, and Immune Cells in Non-Small Cell Lung Cancer Patients with Malignant Pleural Effusion. J Thorac Oncol. 2018 Mar;13(3):447-453. doi: 10.1016/j.jtho.2017.10.034. Epub 2017 Dec 12. PMID: 29246835.

6. Zhang L, Qiang J, Yang X, Wang D, Rehman AU, He X, Chen W, Sheng D, Zhou L, Jiang YZ, Li T, Du Y, Feng J, Hu X, Zhang J, Hu XC, Shao ZM, Liu S. IL1R2 Blockade Suppresses Breast Tumorigenesis and Progression by Impairing USP15-Dependent BMI1 Stability. Adv Sci (Weinh). 2019 Nov 13;7(1):1901728. doi: 10.1002/advs.201901728. PMID: 31921558; PMCID: PMC6947699.

7. Park SL, Gebhardt T, Mackay LK. Tissue-Resident Memory T. Cells in Cancer Immunosurveillance. Trends Immunol. 2019 Aug;40(8):735-47. doi:10.1016/j.it.2019.06.002. Epub 2019 Jun 26. PMID: 31255505.

8. Vitale I, Manic G, Coussens LM, Kroemer G, Galluzzi L. Macrophages and Metabolism in the Tumor Microenvironment. Cell Metab. 2019 Jul 2;30(1):36-50. doi: 10.1016/j.cmet.2019.06.001. PMID: 31269428.

9. Melcher V, Graf M, Interlandi M, Moreno N, de Faria FW, Kim SN, Kastrati D, Korbanka S, Alfert A, Gerß J, Meyer Zu Hörste G, Hartmann W, Frühwald MC, Dugas M, Schüller U, Hasselblatt M, Albert TK, Kerl $\mathrm{K}$. Macrophage-tumor cell interaction promotes ATRT progression and chemoresistance. Acta Neuropathol. 2020 May;139(5):913-936. doi: 10.1007/s00401-019-02116-7. Epub 2019 Dec 17. PMID: 31848709.

10. Hollern DP, Xu N, Thennavan A, Glodowski C, Garcia-Recio S, Mott KR, He X, Garay JP, Carey-Ewend K, Marron D, Ford J, Liu S, Vick SC, Martin M, Parker JS, Vincent BG, Serody JS, Perou CM. B Cells and T Follicular Helper Cells Mediate Response to Checkpoint Inhibitors in High Mutation Burden Mouse Models of Breast Cancer. Cell. 2019 Nov 14;179(5):1191-1206.e21. doi: 10.1016/j.cell.2019.10.028. PMID: 31730857; PMCID: PMC6911685.

11. Bassez A, Vos H, Van Dyck L, Floris G, Arijs I, Desmedt C, Boeckx B, Vanden Bempt M, Nevelsteen I, Lambein K, Punie K, Neven P, Garg AD, Wildiers H, Qian J, Smeets A, Lambrechts D. A single-cell map of intratumoral changes during anti-PD1 treatment of patients with breast cancer. Nat Med. 2021 May;27(5):820-32. doi:10.1038/s41591-021-01323-8. Epub 2021 May 6. PMID: 33958794. 
12. Cristofanilli $M$, Turner NC, Bondarenko I, et al. Fulvestrant plus palbociclib versus fulvestrant plus placebo for treatment of hormone-receptor-positive, HER2-negative metastatic breast cancer that progressed on previous endocrine therapy (PALOMA-3): final analysis of the multicentre, doubleblind, phase 3 randomised controlled trial. Lancet Oncol. 2016;17(4):425-39.

13. Cattin S, et al. "Circulating immune cell populations related to primary breast cancer, surgical removal, and radiotherapy revealed by flow cytometry analysis." Breast cancer research: BCR vol. 23,1 64. 5 Jun. 2021, doi:10.1186/s13058-021-01441-8.

14. Verronèse E, Delgado A, Valladeau-Guilemond J, Garin G, Guillemaut S, Tredan O, Ray-Coquard I, Bachelot T, N'Kodia A, Bardin-Dit-Courageot C, Rigal C, Pérol D, Caux C, Ménétrier-Caux C. Immune cell dysfunctions in breast cancer patients detected through whole blood multi-parametric flow cytometry assay. Oncoimmunology. 2015 Nov 10;5(3):e1100791. doi: 10.1080/2162402X.2015.1100791. PMID: 27141361; PMCID: PMC4839376.

15. Zhang J, Chang L, Zhang X, Zhou Z, Gao Y. Meta-Analysis of the Prognostic and Clinical Value of Tumor-Associated Macrophages in Hepatocellular Carcinoma. J Invest Surg. 2021 Mar;34(3):297306. doi: 10.1080/08941939.2019.1631411. Epub 2019 Aug 15. PMID: 31412745.

16. Fujimura T, Kakizaki A, Furudate S, Kambayashi Y, Aiba S. Tumor-associated macrophages in skin: How to treat their heterogeneity and plasticity. J Dermatol Sci. 2016 Sep;83(3):167-73. doi: 10.1016/j.jdermsci.2016.05.015. Epub 2016 May 25. PMID: 27291068.

17. Mitrofanova I, Zavyalova M, Telegina N, Buldakov M, Riabov V, Cherdyntseva N, Kzhyshkowska J. Tumor-associated macrophages in human breast cancer parenchyma negatively correlate with lymphatic metastasis after neoadjuvant chemotherapy. Immunobiology. 2017 Jan;222(1):101-109. doi: 10.1016/j.imbio.2016.08.001. Epub 2016 Aug 4. PMID: 27510849.

18. Petty AJ, Yang Y. Tumor-associated macrophages: implications in cancer immunotherapy. Immunotherapy. 2017 Mar;9(3):289-302. doi:10.2217/imt-2016-0135. PMID: 28231720; PMCID: PMC5619052.

19. Lou W, Wang W, Chen J, Wang S, Huang Y. ncRNAs-Mediated High Expression of SEMA3F Correlates with Poor Prognosis and Tumor Immune Infifiltration of Hepatocellular Carcinoma. Mol Ther Nucleic Acids. 2021;24:845-55. doi:10.1016/j.omtn.2021.03.014.

20. Wei Y, Ding L, Song X, Tian X, Min N, Guan Q, Li X, Liu M. Tall cell carcinoma with reversed polarity: case report with gene sequencing and literature review. Gland Surg. 2021 Nov;10(11):3147-54. doi:10.21037/gs-21-591. PMID: 34926230; PMCID: PMC8637072.

21. Tu D, Dou J, Wang M, Zhuang H, Zhang X. M2 macrophages contribute to cell proliferation and migration of breast cancer. Cell Biol Int. 2021 Apr;45(4):831-8. doi:10.1002/cbin.11528. Epub 2021 Jan 13. PMID: 33325089.

22. Xie Y, Xie F, Zhang L, Zhou X, Huang J, Wang F, Jin J, Zhang L, Zeng L, Zhou F. Targeted Anti-Tumor Immunotherapy Using Tumor Infiltrating Cells. Adv Sci (Weinh). 2021 Nov;8(22):e2101672. doi:10.1002/advs.202101672. Epub 2021 Oct 18. PMID: 34658167; PMCID: PMC8596143. 
23. Lin B, Du L, Li H, Zhu X, Cui L, Li X. Tumor-infiltrating lymphocytes: Warriors fight against tumors powerfully. Biomed Pharmacother. 2020 Dec;132:110873. doi:10.1016/j.biopha.2020.110873. Epub 2020 Oct 14. PMID: 33068926.

24. Dai Q, Wu W, Amei A, Yan X, Lu L, Wang Z. Regulation and characterization of tumor-infiltrating immune cells in breast cancer. Int Immunopharmacol. 2021 Jan;90:107167. doi:10.1016/j.intimp.2020.107167. Epub 2020 Nov 19. PMID: 33223469; PMCID: PMC7855363.

25. Gerhard GM, Bill R, Messemaker M, Klein AM, Pittet MJ. Tumor-infiltrating dendritic cell states are conserved across solid human cancers. J Exp Med. 2021 Jan 4;218(1):e20200264. doi: 10.1084/jem.20200264. PMID: 33601412; PMCID: PMC7754678.

26. Zhang N, Kim SH, Gainullina A, Erlich EC, Onufer EJ, Kim J, Czepielewski RS, Helmink BA, Dominguez JR, Saunders BT, Ding J, Williams JW, Jiang JX, Segal BH, Zinselmeyer BH, Randolph GJ, Kim KW. LYVE1+ macrophages of murine peritoneal mesothelium promote omentum-independent ovarian tumor growth. J Exp Med. 2021 Dec 6;218(12):e20210924. doi: 10.1084/jem.20210924. Epub 2021 Oct 29. PMID: 34714329; PMCID: PMC8575007.

27. Rodriguez E, Boelaars K, Brown K, Eveline Li RJ, Kruijssen L, Bruijns SCM, van Ee T, Schetters STT, Crommentuijn MHW, van der Horst JC, van Grieken NCT, van Vliet SJ, Kazemier G, Giovannetti E, Garcia-Vallejo JJ, van Kooyk Y. Sialic acids in pancreatic cancer cells drive tumour-associated macrophage differentiation via the Siglec receptors Siglec-7 and Siglec-9. Nat Commun. 2021 Feb 24;12(1):1270. doi: 10.1038/s41467-021-21550-4. PMID: 33627655; PMCID: PMC7904912.

28. Cai B, Dongiovanni P, Corey KE, Wang X, Shmarakov IO, Zheng Z, Kasikara C, Davra V, Meroni M, Chung RT, Rothlin CV, Schwabe RF, Blaner WS, Birge RB, Valenti L, Tabas I. Macrophage MerTK Promotes Liver Fibrosis in Nonalcoholic Steatohepatitis. Cell Metab. 2020 Feb 4;31(2):406-421.e7. doi: 10.1016/j.cmet.2019.11.013. Epub 2019 Dec 12. PMID: 31839486; PMCID: PMC7004886.

29. Rőszer T. Understanding the Mysterious M2 Macrophage through Activation Markers and Effector Mechanisms. Mediators Inflamm. 2015;2015:816460. doi:10.1155/2015/816460. Epub 2015 May 18. PMID: 26089604; PMCID: PMC4452191.

30. Dong LQ, Peng LH, Ma LJ, Liu DB, Zhang S, Luo SZ, Rao JH, Zhu HW, Yang SX, Xi SJ, Chen M, Xie FF, Li FQ, Li WH, Ye C, Lin LY, Wang YJ, Wang XY, Gao DM, Zhou H, Yang HM, Wang J, Zhu SD, Wang XD, Cao Y, Zhou J, Fan J, Wu K, Gao Q. Heterogeneous immunogenomic features and distinct escape mechanisms in multifocal hepatocellular carcinoma. J Hepatol. 2020 May;72(5):896-908. doi:10.1016/j.jhep.2019.12.014. Epub 2019 Dec 27. PMID: 31887370.

31. Wu JY, Huang TW, Hsieh YT, Wang YF, Yen CC, Lee GL, Yeh CC, Peng YJ, Kuo YY, Wen HT, Lin HC, Hsiao CW, Wu KK, Kung HJ, Hsu YJ, Kuo CC. Cancer-Derived Succinate Promotes Macrophage Polarization and Cancer Metastasis via Succinate Receptor. Mol Cell. 2020 Jan 16;77(2):213-227.e5. doi: 10.1016/j.molcel.2019.10.023. Epub 2019 Nov 14. PMID: 31735641.

32. Kuo CH, Tsai ML, Li CH, Hsiao HP, Chao MC, Lee MS, Lin YC, Hung CH. Altered Pattern of Macrophage Polarization as a Biomarker for Severity of Childhood Asthma. J Inflamm Res. 2021 Nov 18;14:6011-6023. doi: 10.2147/JIR.S319754. PMID: 34819741; PMCID: PMC8608023. 
33. Saadi F, Chakravarty D, Kumar S, Kamble M, Saha B, Shindler KS, Das Sarma J. CD40L protects against mouse hepatitis virus-induced neuroinflammatory demyelination. PLoS Pathog. 2021 Dec 13;17(12):e1010059. doi: 10.1371/journal.ppat.1010059. Epub ahead of print. PMID: 34898656.

34. Kong X, Zhu M, Wang Z, Xu Z, Shao J. Characteristics and clinical significance of CD163+/CD206+M2 mono-macrophage in the bladder cancer microenvironment. Turk J Biol. 2021 Oct 18;45(5):624-632. doi: 10.3906/biy-2104-17. PMID: 34803459; PMCID: PMC8574194.

35. Proctor DT, Huang J, Lama S, Albakr A, Van Marle G, Sutherland GR. Tumor-associated macrophage infiltration in meningioma. Neurooncol Adv. 2019 Sep 19;1(1):vdz018. doi: 10.1093/noajnl/vdz018. PMID: 32642654; PMCID: PMC7212927.

36. Ahirwar DK, Charan M, Mishra S, Verma AK, Shilo K, Ramaswamy B, Ganju RK. Slit2 Inhibits Breast Cancer Metastasis by Activating M1-Like Phagocytic and Antifibrotic Macrophages. Cancer Res. 2021 Oct 15;81(20):5255-5267. doi: 10.1158/0008-5472.CAN-20-3909. Epub 2021 Aug 16. PMID: 34400395; PMCID: PMC8631742.

37. Henriet P, Emonard H. Matrix metalloproteinase-2: Not (just) a "hero" of the past. Biochimie. 2019 Nov;166:223-32. doi:10.1016/j.biochi.2019.07.019. Epub 2019 Jul 27. PMID: 31362036.

38. Lin X, Wang S, Sun M, Zhang C, Wei C, Yang C, Dou R, Liu Q, Xiong B. miR-195-5p/NOTCH2-mediated EMT modulates IL-4 secretion in colorectal cancer to affect M2-like TAM polarization. J Hematol Oncol. 2019 Feb 26;12(1):20. doi: 10.1186/s13045-019-0708-7. Erratum in: J Hematol Oncol. 2019 Nov 22;12(1):122. PMID: 30808369; PMCID: PMC6390326.

39. Xu C, Yang S, Jiang Z, Zhou J, Yao J. Self-Propelled Gemini-like LMWH-Scaffold Nanodrugs for Overall Tumor Microenvironment Manipulation via Macrophage Reprogramming and Vessel Normalization. Nano Lett. 2020 Jan 8;20(1):372-383. doi: 10.1021/acs.nanolett.9b04024. Epub 2019 Dec 18. Erratum in: Nano Lett. 2021 Jan 13;21(1):889. PMID: 31840517.

40. Osborne N, Sundseth R, Gay MD, Cao H, Tucker RD, Nadella S, Wang S, Liu X, Kroemer A, Sutton L, Cato A, Smith JP. Vaccine against gastrin, a polyclonal antibody stimulator, decreases pancreatic cancer metastases. Am J Physiol Gastrointest Liver Physiol. 2019 Nov 1;317(5):G682-G693. doi: 10.1152/ajpgi.00145.2019. Epub 2019 Aug 21. PMID: 31433212; PMCID: PMC6879893.

41. Najafi M, Farhood B, Mortezaee K. Extracellular matrix (ECM) stiffness and degradation as cancer drivers. J Cell Biochem. 2019 Mar;120(3):2782-2790. doi: 10.1002/jcb.27681. Epub 2018 Oct 15. PMID: 30321449.

42. Liu J, Geng $X$, Hou J, Wu G. New insights into M1/M2 macrophages: key modulators in cancer progression. Cancer Cell Int. 2021 Jul 21;21(1):389. doi: 10.1186/s12935-021-02089-2. PMID: 34289846; PMCID: PMC8296555.

43. Franklin RA, Liao W, Sarkar A, Kim MV, Bivona MR, Liu K, Pamer EG, Li MO. The cellular and molecular origin of tumor-associated macrophages. Science. 2014 May 23;344(6186):921-5. doi: 10.1126/science.1252510. Epub 2014 May 8. PMID: 24812208; PMCID: PMC4204732.

44. Hung $\mathrm{CH}$, Chen FM, Lin YC, Tsai ML, Wang SL, Chen YC, Chen YT, Hou MF. Altered monocyte differentiation and macrophage polarization patterns in patients with breast cancer. BMC Cancer. 
2018 Apr 3;18(1):366. doi: 10.1186/s12885-018-4284-y. PMID: 29614988; PMCID: PMC5883269.

45. Chen C, Yang RX, Xu HG. STING and liver disease. J Gastroenterol. 2021 Aug;56(8):704-12. doi:10.1007/s00535-021-01803-1. Epub 2021 Jun 23. PMID: 34159442; PMCID: PMC8219471.

46. Jefferies CA. Regulating IRFs in IFN Driven Disease. Front Immunol. 2019 Mar 29;10:325. doi: 10.3389/fimmu.2019.00325. PMID: 30984161; PMCID: PMC6449421.

47. Trindade BC, Chen GY. NOD1 and NOD2 in inflammatory and infectious diseases. Immunol Rev. 2020 Sep;297(1):139-61. doi:10.1111/imr.12902. Epub 2020 Jul 17. PMID: 32677123.

48. Gradishar WJ, Moran MS, Abraham J, Aft R, Agnese D, Allison KH, Blair SL, Burstein HJ, Dang C, Elias AD, Giordano SH, Goetz MP, Goldstein LJ, Hurvitz SA, Isakoff SJ, Jankowitz RC, Javid SH, Krishnamurthy J, Leitch M, Lyons J, Matro J, Mayer IA, Mortimer J, O'Regan RM, Patel SA, Pierce LJ, Rugo HS, Sitapati A, Smith KL, Smith ML, Soliman H, Stringer-Reasor EM, Telli ML, Ward JH, Wisinski KB, Young JS, Burns JL, Kumar R. NCCN Guidelines ${ }^{\circledR}$ Insights: Breast Cancer, Version 4.2021. J Natl Compr Canc Netw. 2021 May 1;19(5):484-493. doi: 10.6004/jnccn.2021.0023. PMID: 34794122.

49. Lee SW, Lee HY, Kang SW, Kim MJ, Lee YJ, Sung CO, Kim YM. Application of Immunoprofiling Using Multiplexed Immunofluorescence Staining Identifies the Prognosis of Patients with High-Grade Serous Ovarian Cancer. Int J Mol Sci. 2021 Sep 6;22(17):9638. doi: 10.3390/ijms22179638. PMID: 34502561; PMCID: PMC8431807.

\section{Tables}

Due to technical limitations, table 1 is only available as a download in the Supplemental Files section.

\section{Figures}




\section{A}
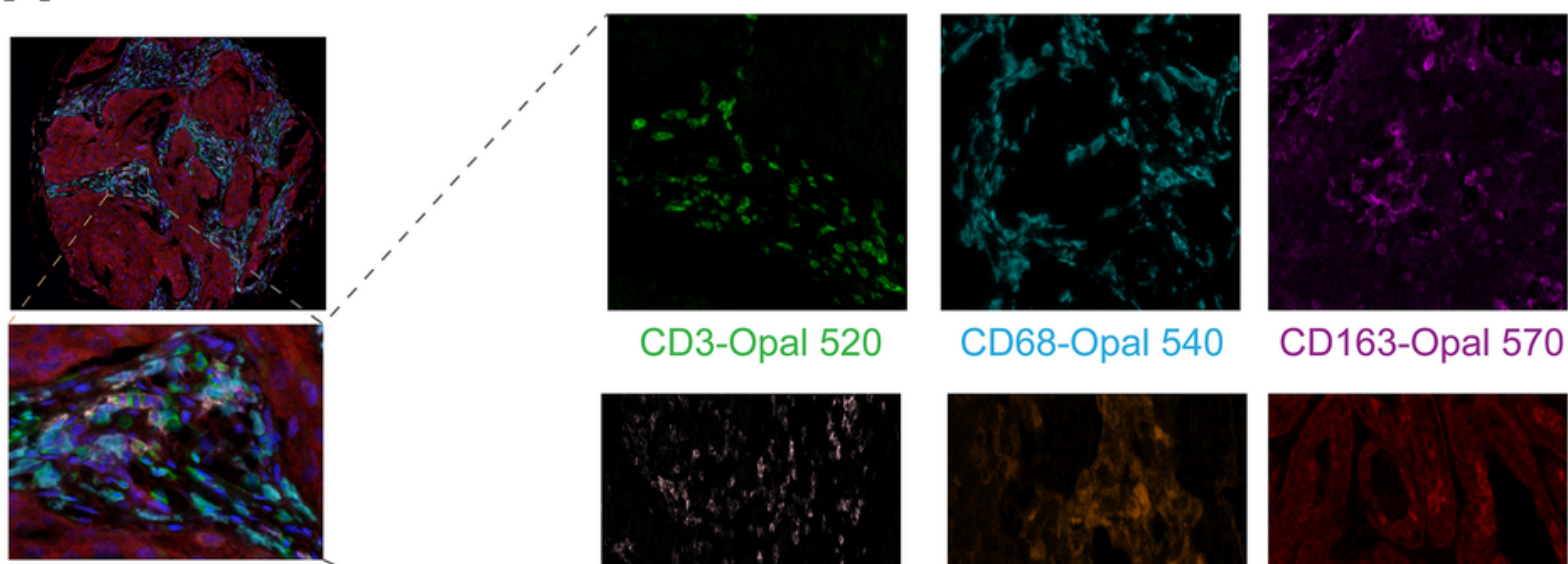

CD3-Opal 520

CD68-Opal 540

CD163-Opal 570
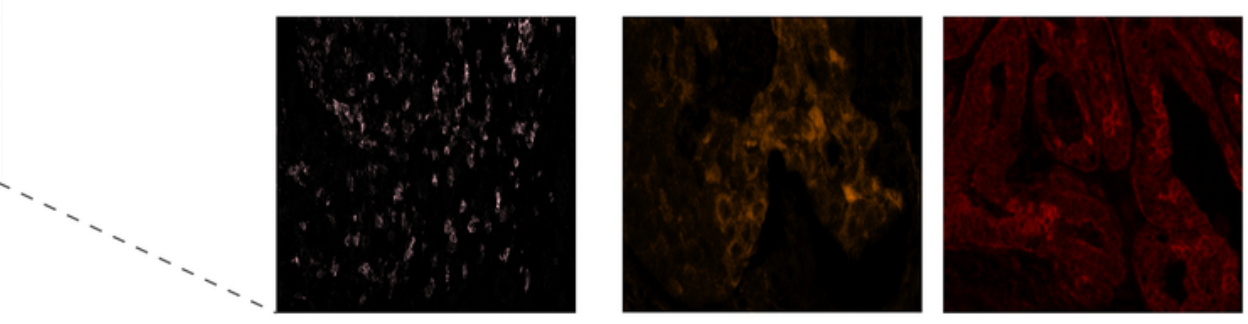

CD19-Opal 620

CD40-Opal 650

TLR4-Opal 670

\section{B}
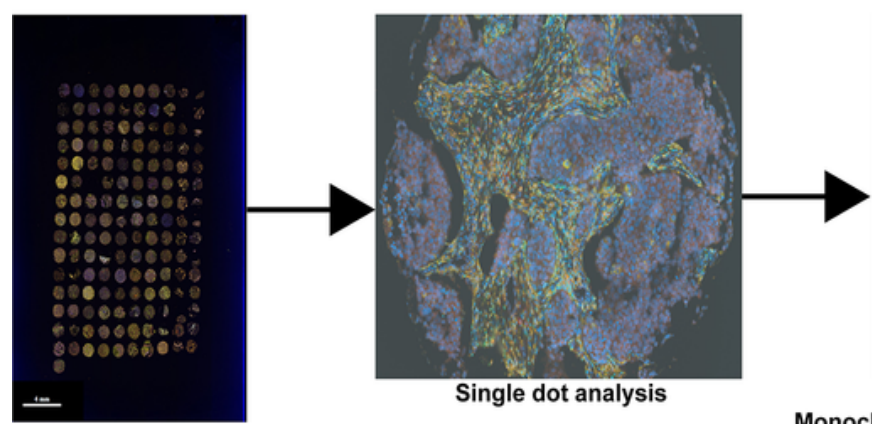

Single dot analysis

Single channel split

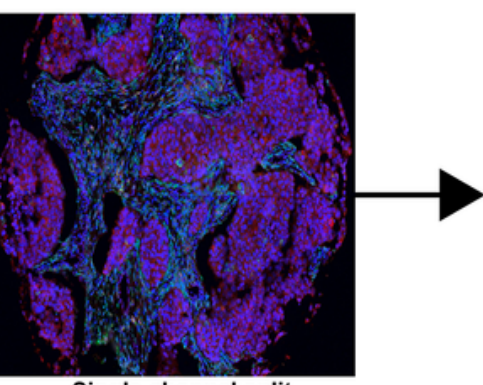
Monochromatic fluorescence intensity compensation

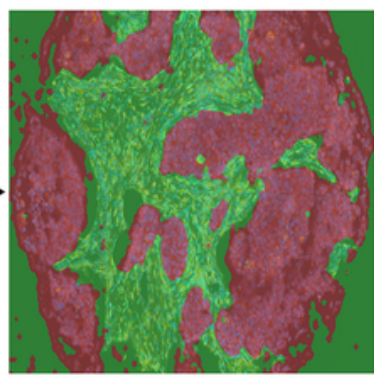

Segment division or skip
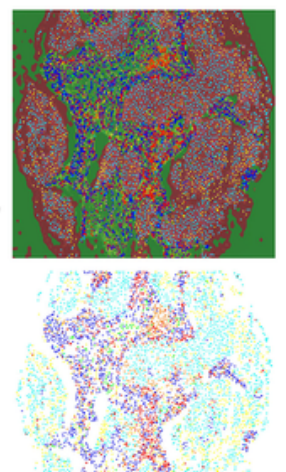

W.
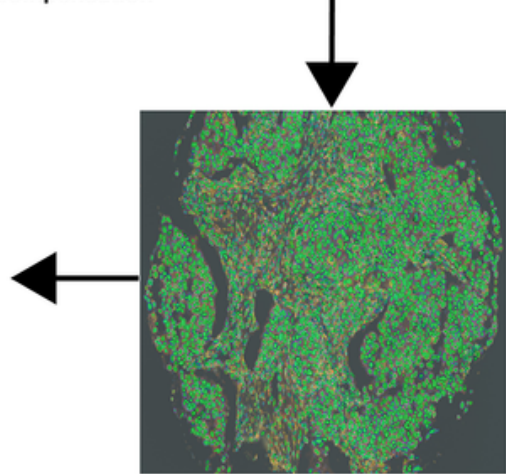

Nuclei selection

Phenotype map in segment or total

\section{Figure 1}

The immune cell phenotypes analysis flow chart with InForm software.

Images were captured at 200x magnification with AKOYA-Vectra 3, and were analyzed with InForm 2.1 software. A) Multiple fluorescent dyes were coupled as follows: Opal 520 for anti-CD3 (green), Opal 540 for anti-CD68 (blue), Opal 570 for anti-CD163 (purple), Opal 620 for anti-CD19 (pink), Opal 650 for anti- 
CD40 (orange), and Opal 690 for anti-TLR4 (red) as showed. B) Each sample was analyzed individually with 6 phenotype markers in total or segmental areas as displayed.
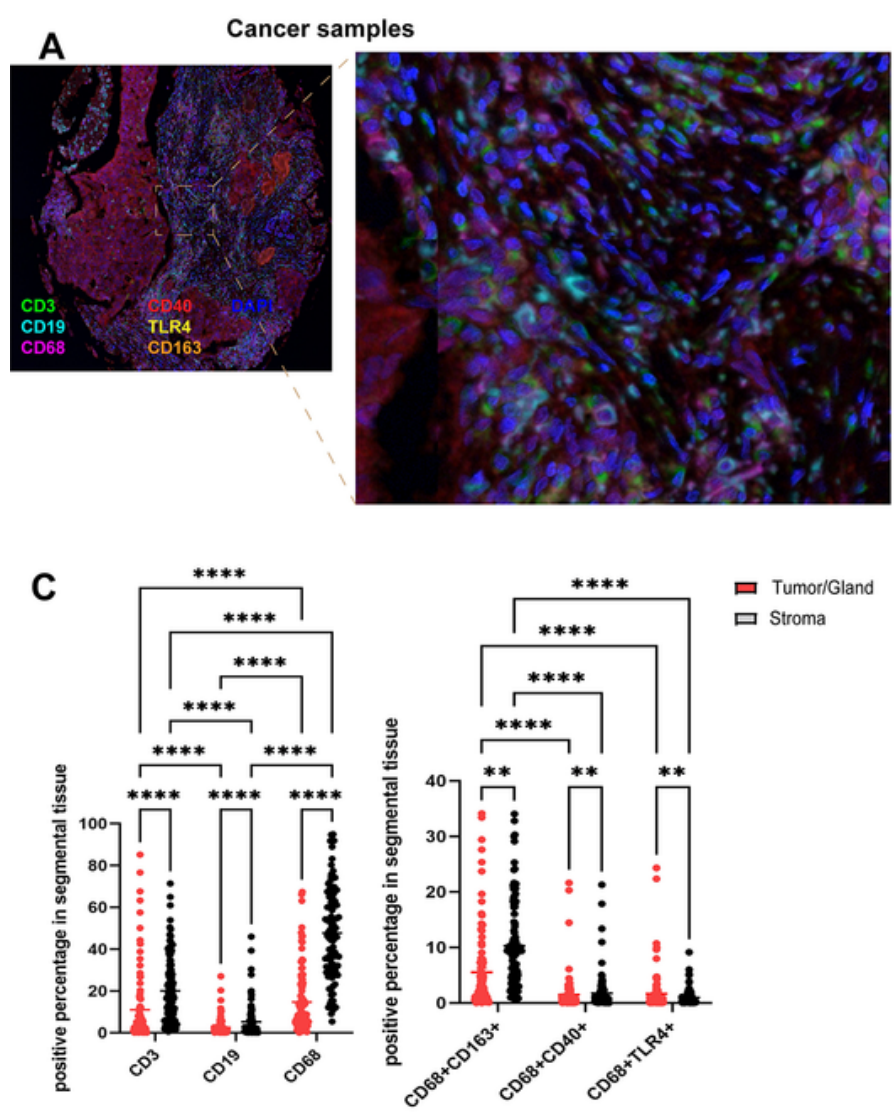

ㅁ Tumor/Gland 口 Stroma
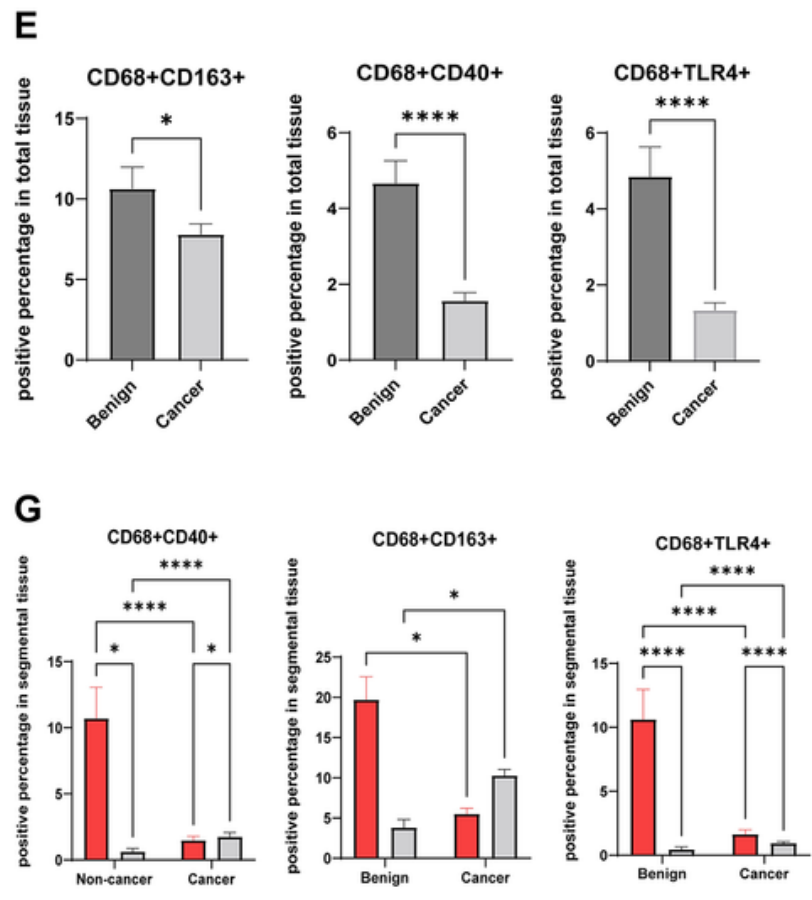

B
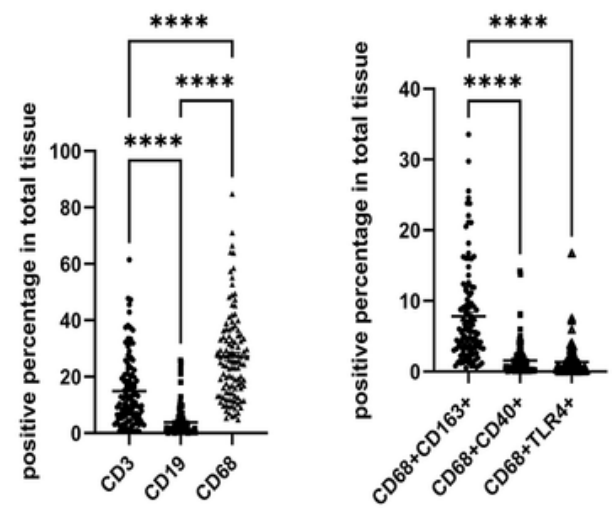

D

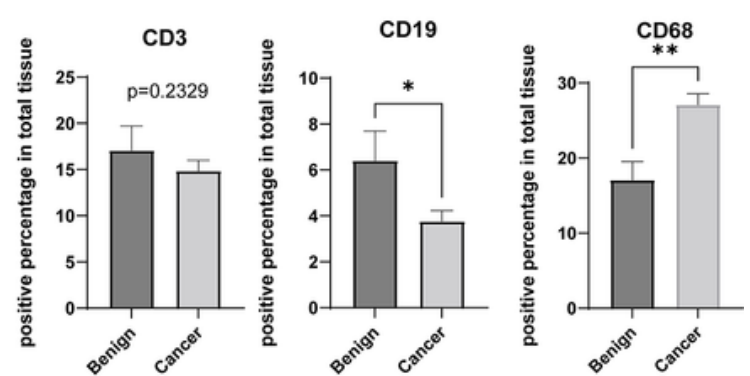

$\mathbf{F}$
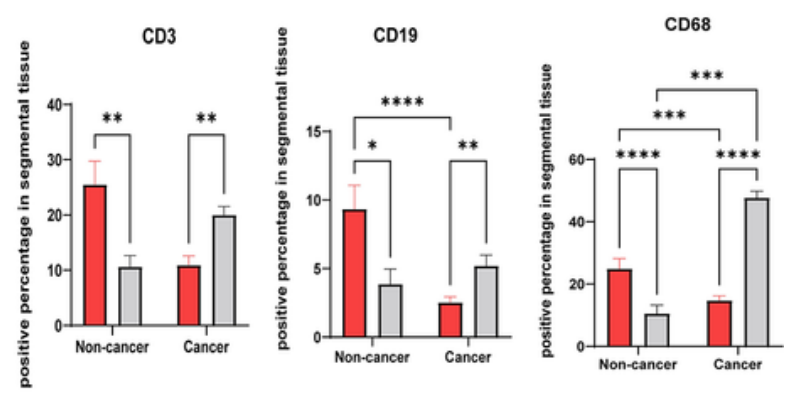

Figure 2

The general immune phenotype analysis between non-carcinoma and carcinoma tissues in total or segmental areas. 
Percentages of $\mathrm{CD}^{+} \mathrm{T}$ cells, $\mathrm{CD} 19^{+} \mathrm{B}$ cells, $\mathrm{CD} 68^{+}$macrophages and their subtypes (CD68 ${ }^{+} \mathrm{TLR} 4^{+} \mathrm{M} 1$, $\mathrm{CD} 68^{+} \mathrm{CD}_{163^{+}} \mathrm{M} 2$ and $\mathrm{CD} 68^{+} \mathrm{CD} 40^{+} \mathrm{TAM}$ ) were compared between the non-carcinoma and carcinoma tissues in total or segmental areas. A) Image from one cancer sample and showed the stromal infiltrating immune cells. B-C) The contradistinctions among T cells, B cells, macrophages and their subtypes of carcinoma samples in total area B), and in segmental areas $\mathbf{C}$ ) in cancer samples. D-G) The comparisons between the benign and carcinoma samples in total area $\mathbf{D}-\mathbf{E})$, and in segmental areas F-G). The data were analyzed with the 2-way and one-way ANOVA with Tukey test or 2-tailed unpaired t test. *, $p<0.05$; **, $p<0.01 ; * \star \star, p<0.005 ; * \star \star \star, p<0.001$. 
A

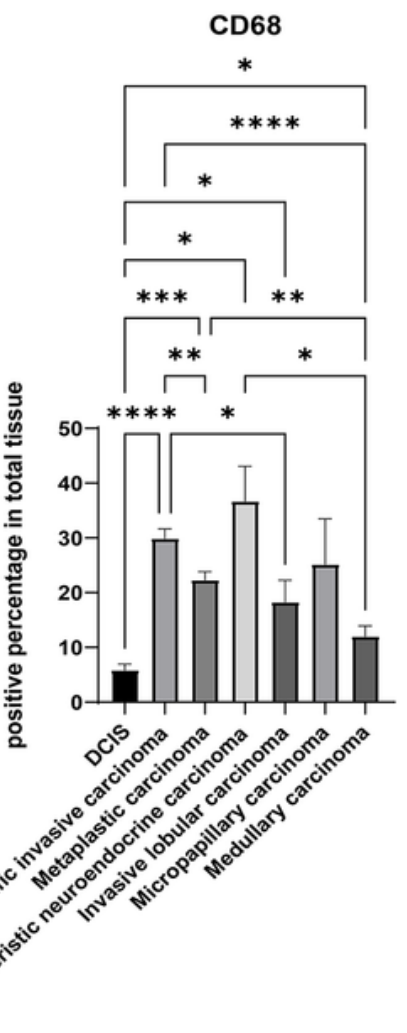

B

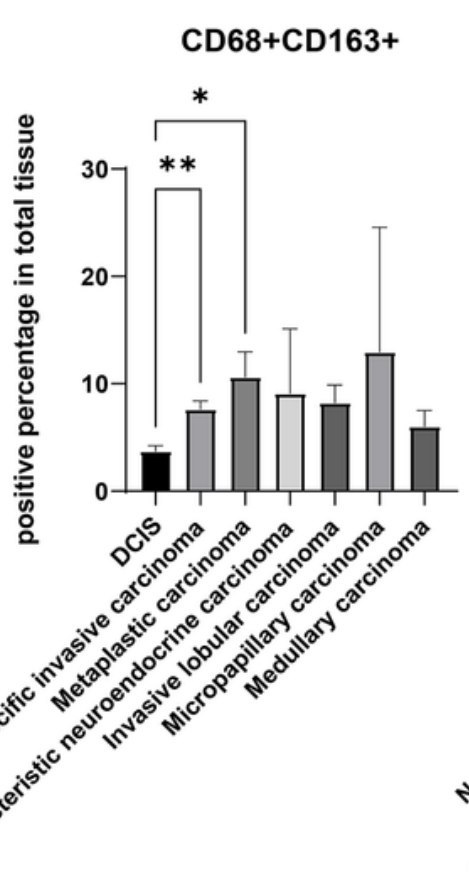

CD68+TLR4+

CD68+CD40+
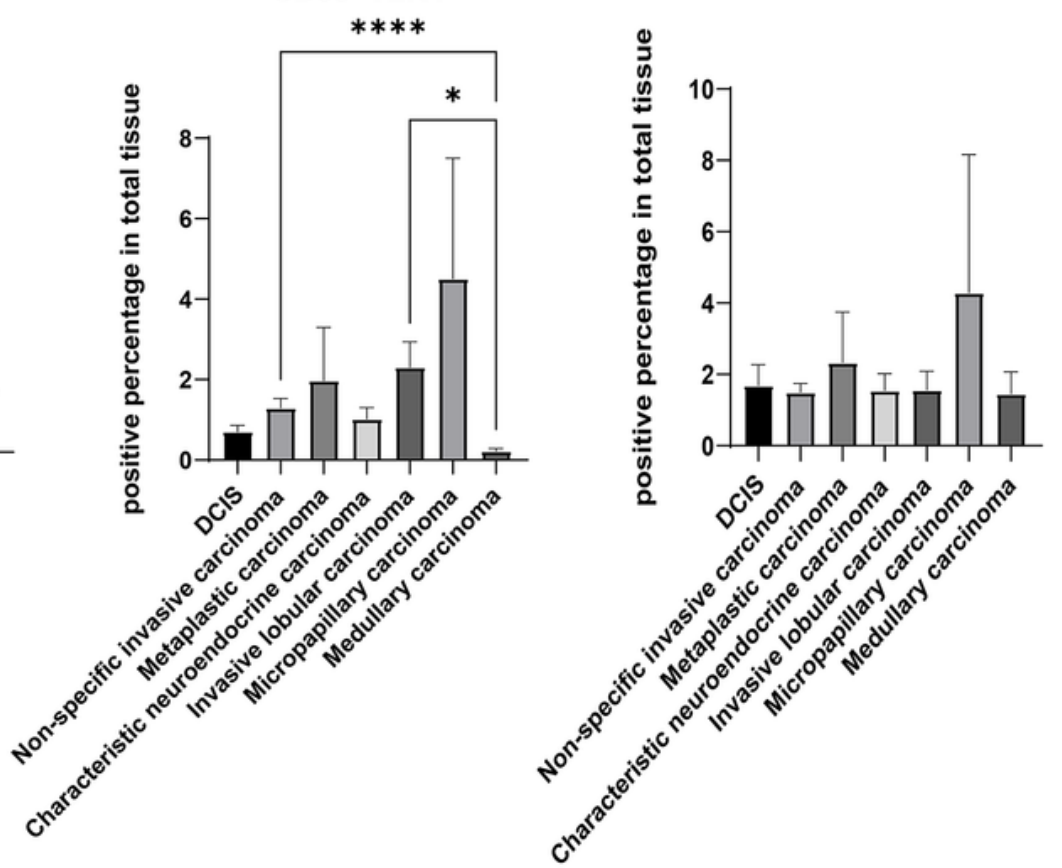

Figure 3

The immune phenotype analysis among different pathological types of the malignant tissues.

A) The percentages of T cells, B cells and macrophages. B) The percentages of macrophage subtypes. The data were analyzed with the 2-way and one-way ANOVA with Tukey test or 2-tailed unpaired $\mathrm{t}$ test. *, $p<0.05 ; * \star, p<0.01 ; * \star \star, p<0.005 ; * \star \star \star, p<0.001$. 
A
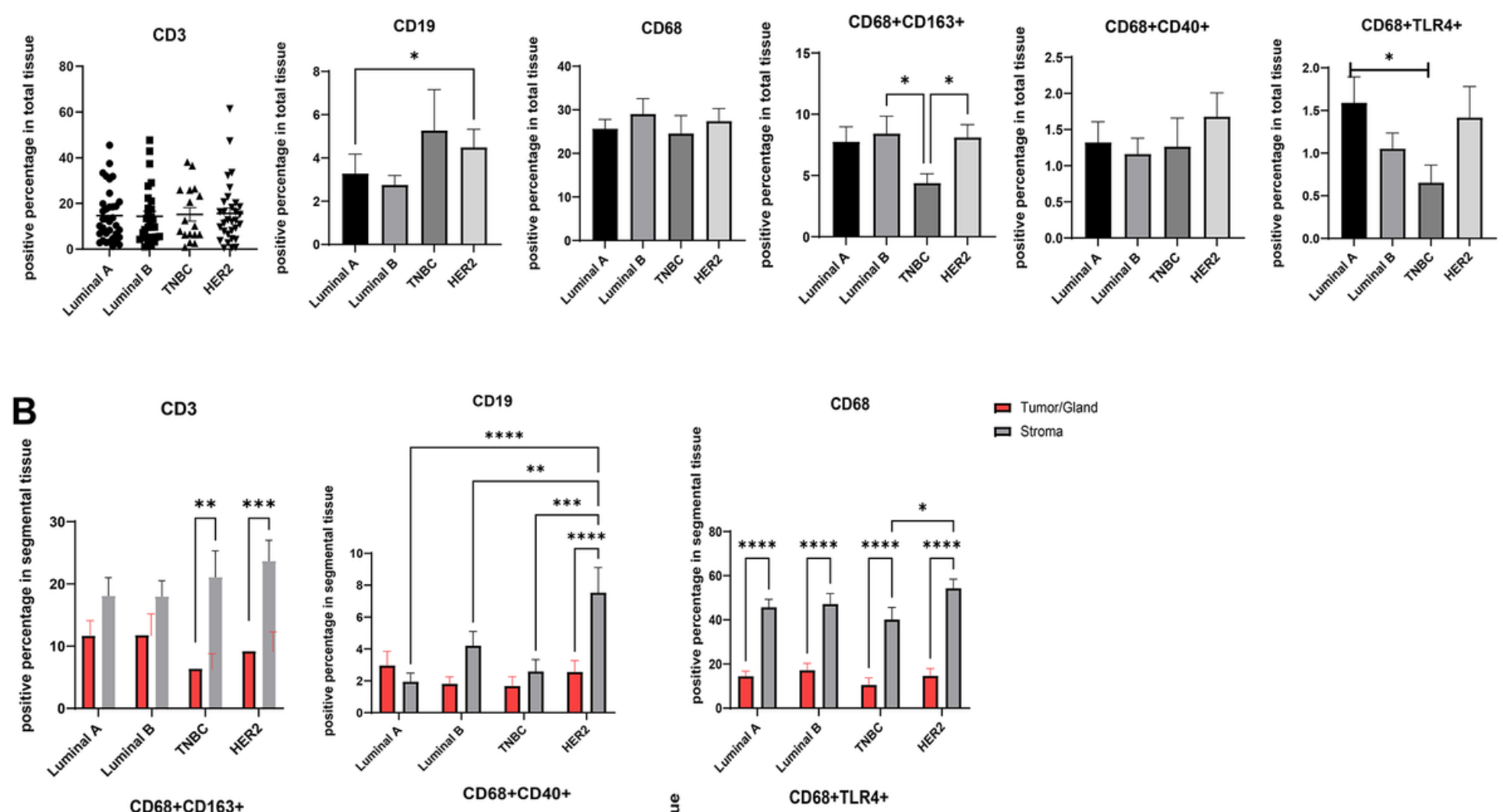

口 Tumor/Gland

口 Stroma
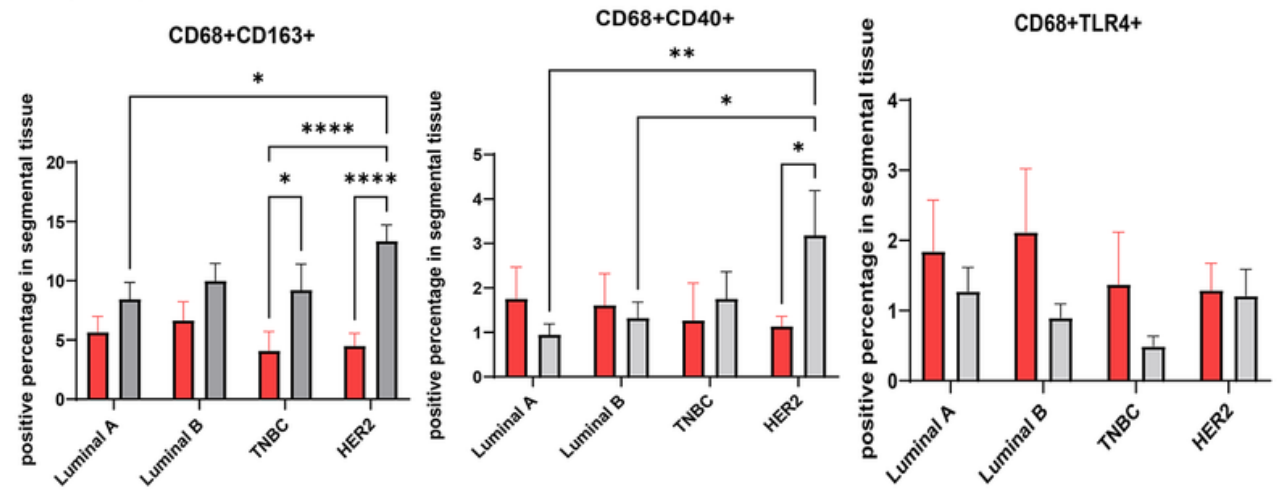

Figure 4

The immune phenotype analysis among different molecular types of malignant tissues in total or segmental areas.

A) The general immunoprofiles among different molecular types in total area. B) In segmental areas, the different immune cells among different molecular types. The data were analyzed with the 2-way and oneway ANOVA with Tukey test or 2-tailed unpaired t test. ${ }^{*}, p<0.05 ;{ }^{* \star}, p<0.01 ; * \star *, p<0.005 ; * \star \star \star, p<0.001$. 

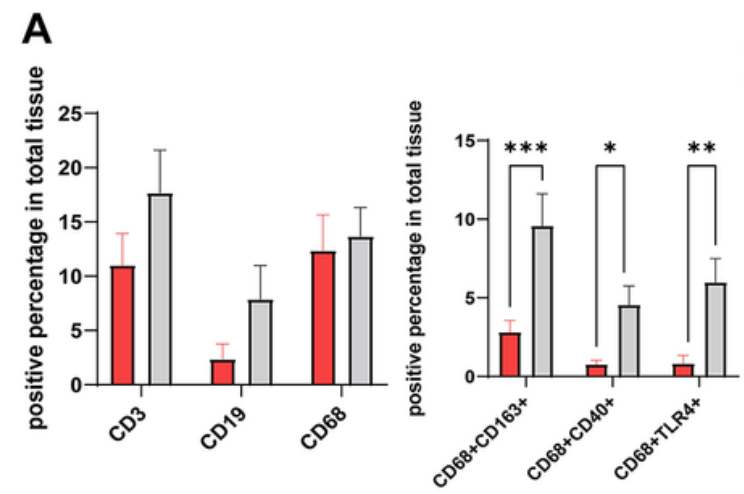

C Para-cancer samples
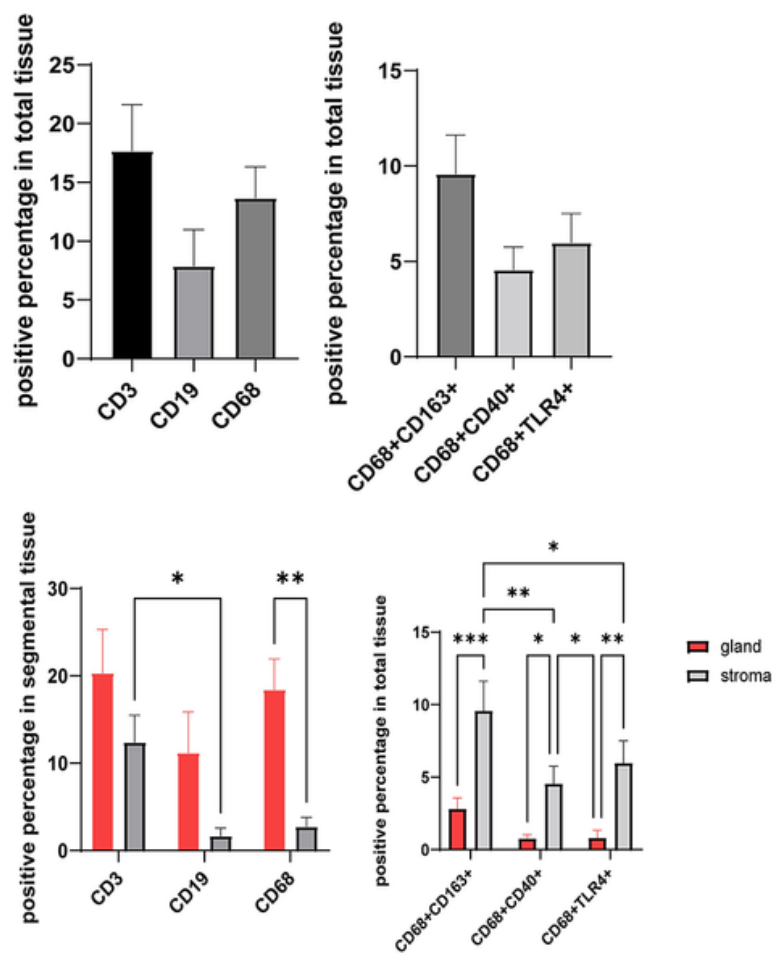

B Para-cancer MI/IHC

口 cancer
口 para-cancer
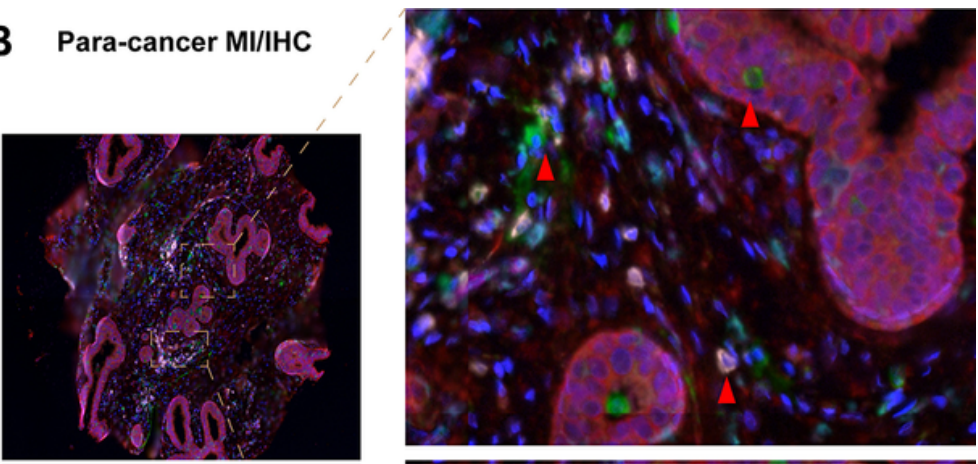

Cancer MI/IHC
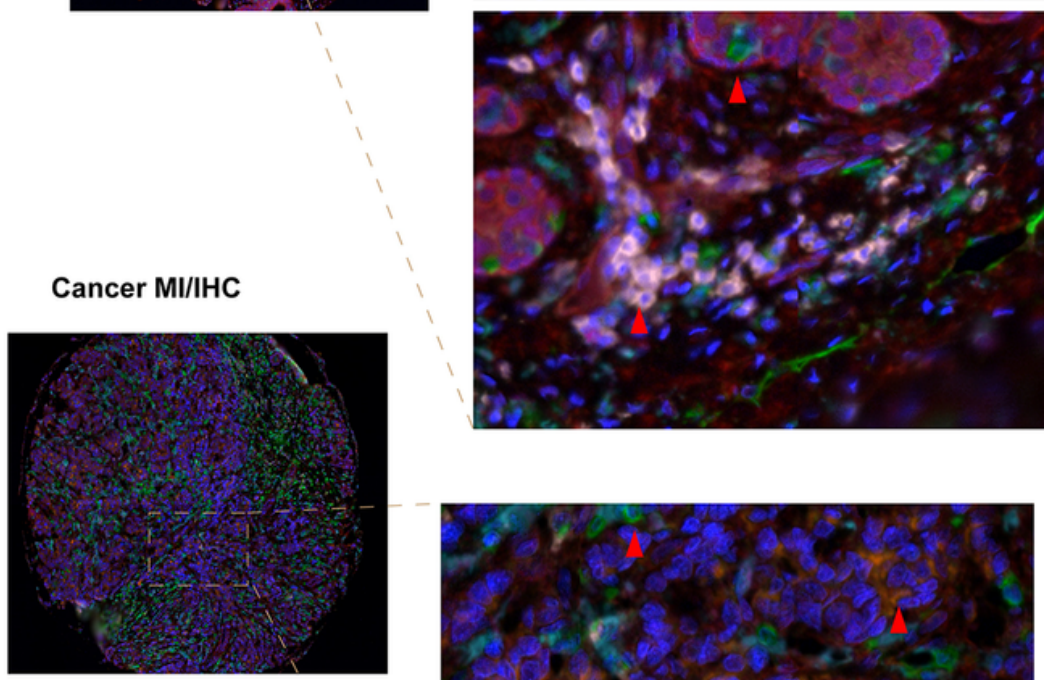

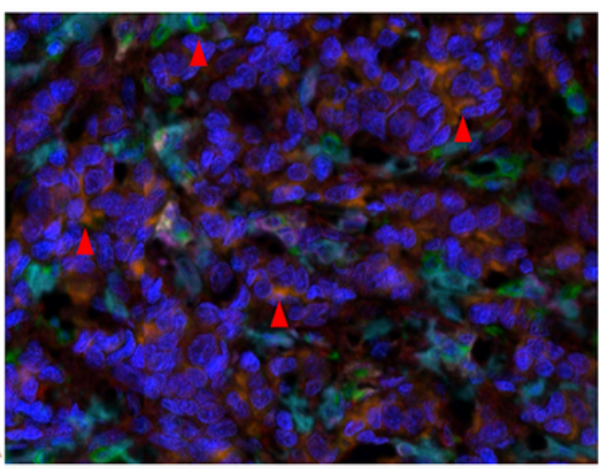

Figure 5

The immune phenotype analysis between the para-cancer and cancer tissues.

A) The general immune profiles between the para-cancer and cancer tissues including $T$ cells, $B$ cells, macrophages and macrophage subtypes. B) Images from para-cancer and cancer samples. Red arrows showed different immune cells in gland areas or stromal ares. C) The immunoprofiles in the para-cancer samples in total and segmental areas. The data were analyzed with the 2-way and one-way ANOVA with Tukey test or 2-tailed unpaired t test. *, $p<0.05 ; \star \star, p<0.01 ; * \star \star, p<0.005 ; \star \star \star \star, p<0.001$. 
A
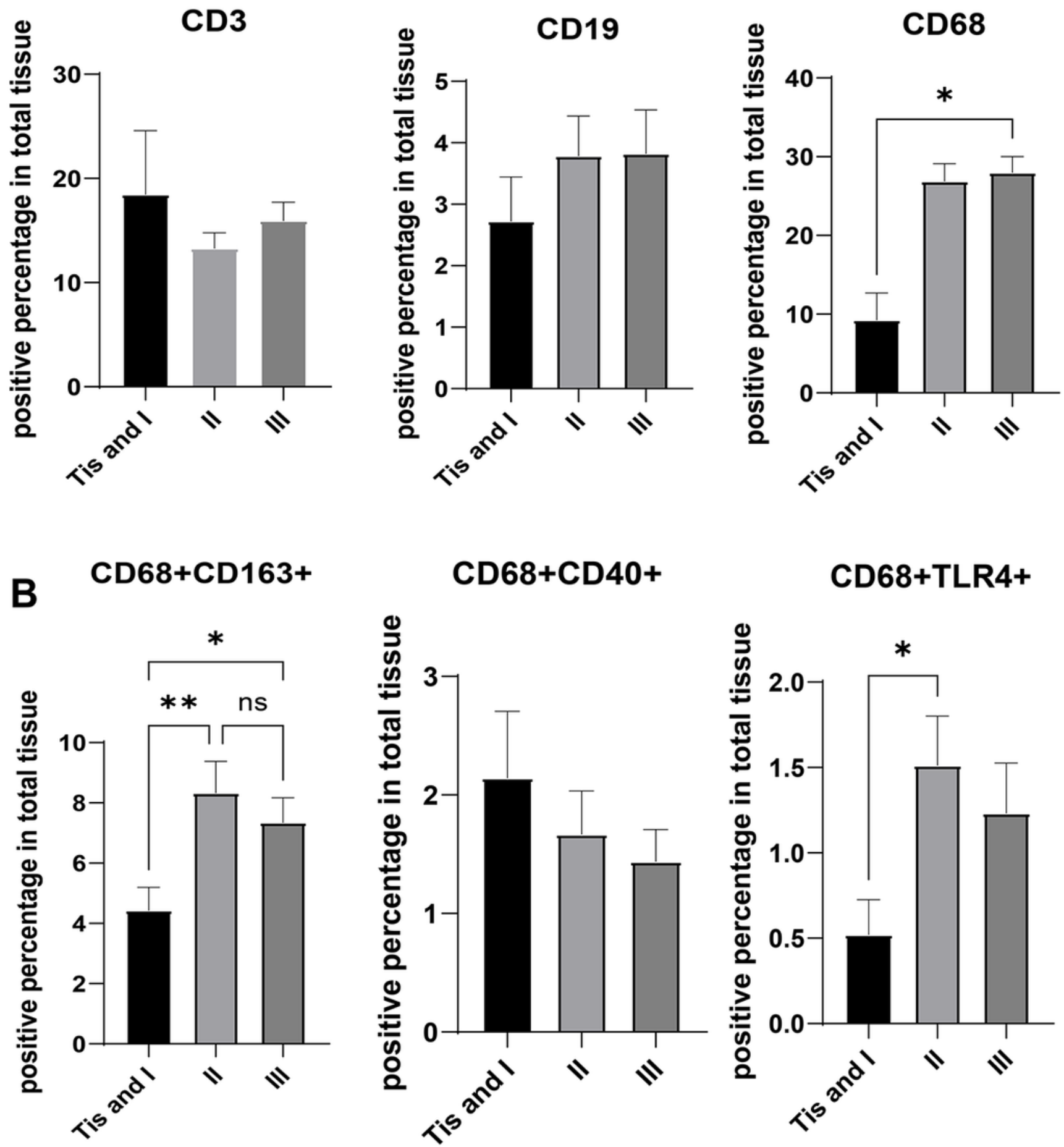

Figure 6

The immune phenotype analysis among different clinical stages.

A) The general immunoprofiles among stages of Tis-I, II and III tissues including T cells, B cells and macrophages. B) The percentages of macrophage subtypes. The data were analyzed with the 2-way and 
one-way ANOVA with Tukey test or 2-tailed unpaired t test. *, $p<0.05 ; * \star, p<0.01 ; * \star \star, p<0.005 ; * \star \star \star$, $p<0.001$.
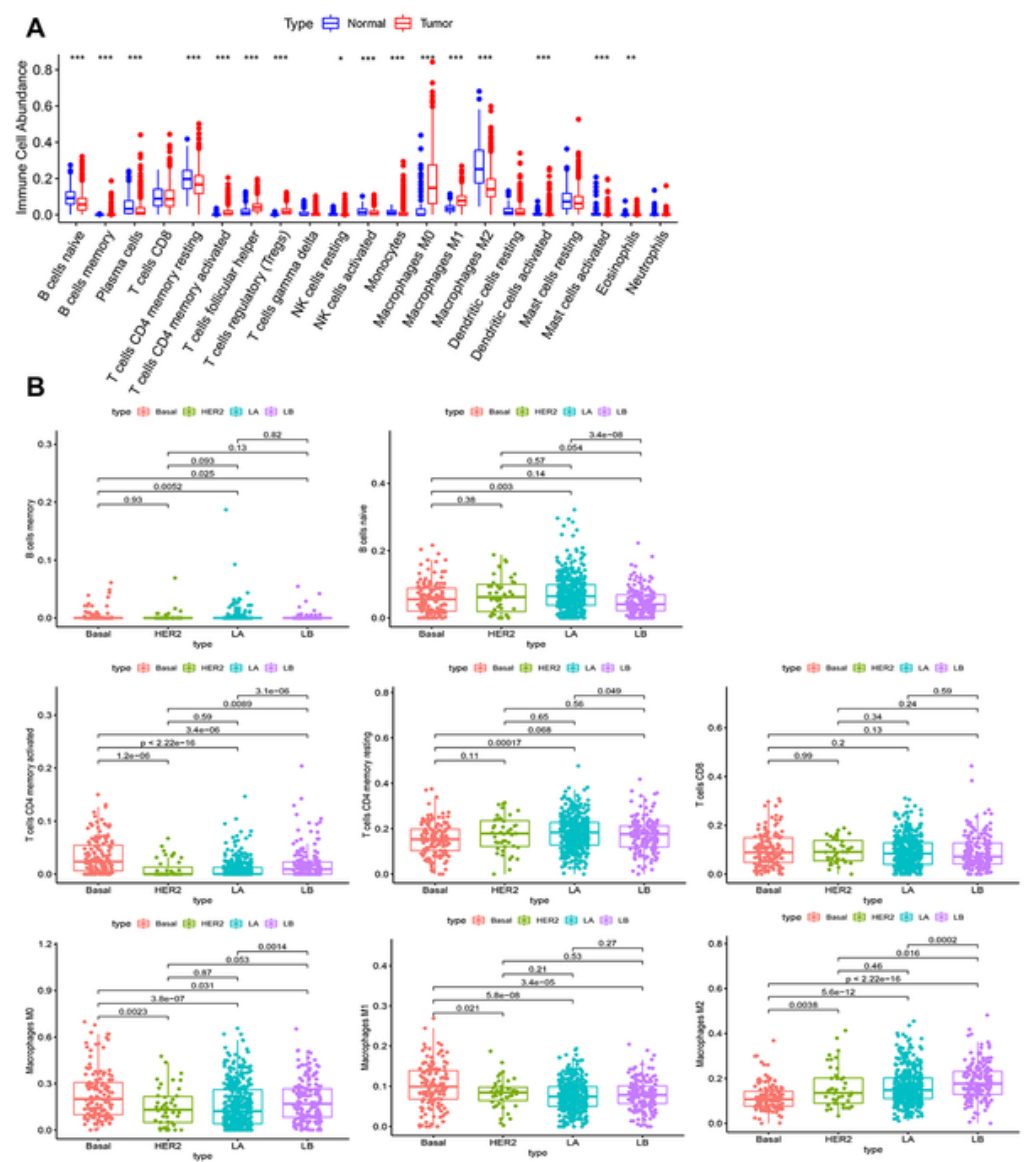

C
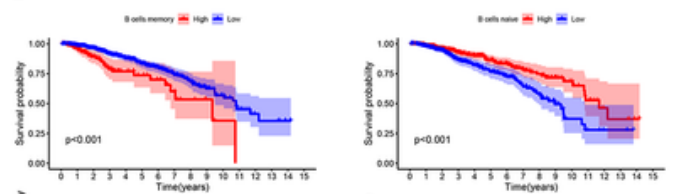

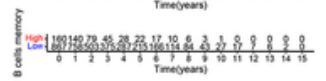
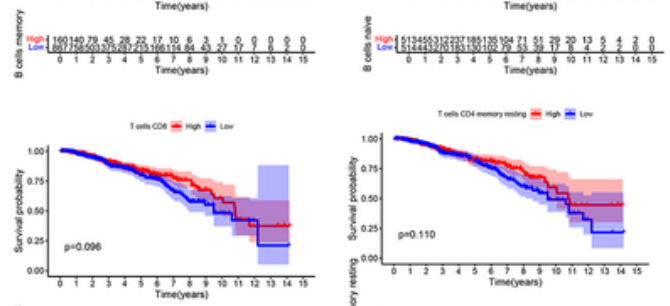

8.
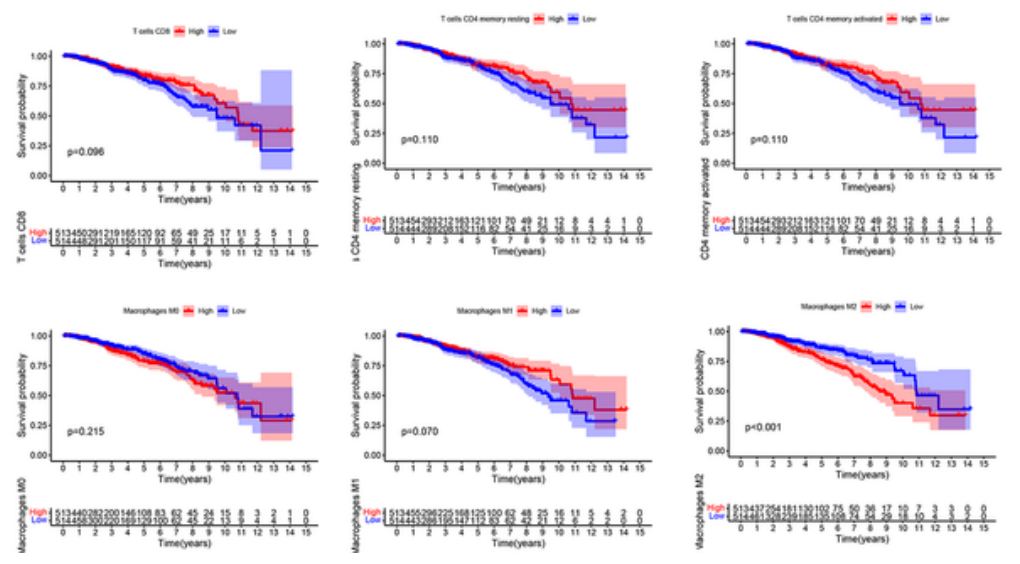

Figure 7 
Survival and correlation analysis of various immune cells according to bioinformatic data.

A) The cell abundance map of 21 immune cell types in breast cancer compared with normal tissues. B) The immune cell abundance of different subtypes of B cells, $T$ cells and macrophages among various molecular types. C) Survival analysis of immune cells in breast cancer. The data were analyzed with the 2-way and one-way ANOVA with Tukey test or 2-tailed unpaired t test. ${ }^{*}, p<0.05 ;{ }^{* *}, p<0.01 ; * \star *, p<0.005$; $\star \star \star \star, ~ p<0.001$.
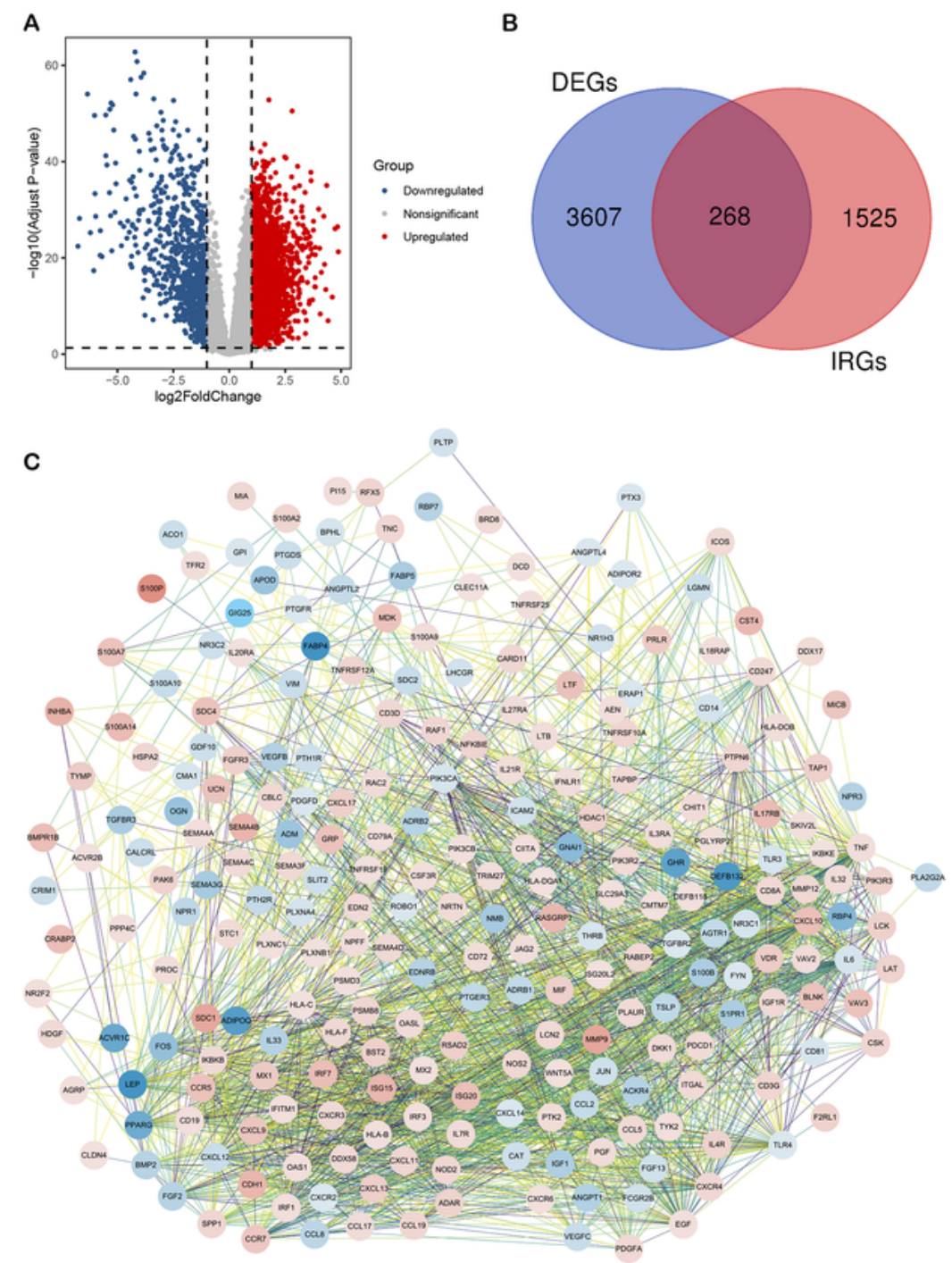

D

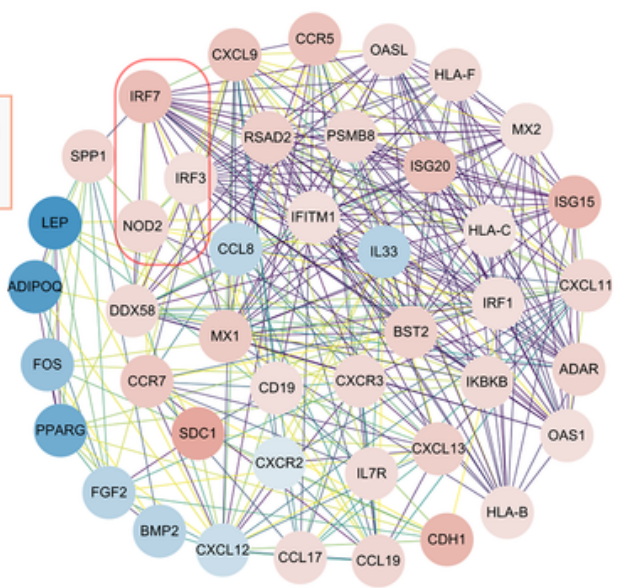


Figure 8

DEG analysis correlated with potential macrophage-related biological functions of breast cancer.
A) DEG identification based on GSE42568 dataset.
B) The overlapping genes between DEGs and IRGs. C) PPI network constructed by 268 overlapping genes. D) The most significant module sorted out from PPI network and potential macrophage-related biological process enriched by the 3 framed genes.

\section{Supplementary Files}

This is a list of supplementary files associated with this preprint. Click to download.

- Table1.pdf

- SFigure1.jpg

- SFigure2.jpg

- SFigure3.pdf

- SFigure4.pdf

- SFigure5.pdf

- SFigure6.pdf

- STable.pdf 